Review Article

\title{
Controllable Processing Times in Project and Production Management: Analysing the Trade-Off between Processing Times and the Amount of Resources
}

\author{
Victor Fernandez-Viagas and Jose M. Framinan \\ Industrial Management, School of Engineering, University of Seville, Camino de los Descubrimientos, s/n, 41092 Seville, Spain \\ Correspondence should be addressed to Victor Fernandez-Viagas; vfernandezviagas@us.es
}

Received 4 December 2014; Revised 10 February 2015; Accepted 17 February 2015

Academic Editor: Hang Xu

Copyright (C) 2015 V. Fernandez-Viagas and J. M. Framinan. This is an open access article distributed under the Creative Commons Attribution License, which permits unrestricted use, distribution, and reproduction in any medium, provided the original work is properly cited.

\begin{abstract}
The amount of resources assigned to a task highly influences its processing time. Traditionally, different functions have been used in the literature in order to map the processing time of the task with the amount of resources assigned to the task. Obviously, this relation depends on several factors such as the type of resource and/or decision problem under study. Although in the literature there are hundreds of papers using these relations in their models or methods, most of them do not justify the motivation for choosing a specific relation over another one. In some cases, even wrong justifications are given and, hence, infeasible or nonappropriated relations have been applied for the different problems, as we will show in this paper. Thus, our paper intends to fill this gap establishing the conditions where each relation can be applied by analysing the relations between the processing time of a task and the amount of resources assigned to that task commonly employed in the production and project management literature.
\end{abstract}

\section{Introduction}

The completion time of a project (project lead time) has turned out to be one of the main sources of competitive advantage for companies (see, e.g., $[1,2])$. This lead time depends on the processing time of each task in the project and, traditionally, these processing times have been assumed to be fixed data. However, in real life, they are usually dependent on the amount of resources assigned to the tasks [3]. In this case, they are denoted as controllable processing times, and it is then assumed that jobs can be accomplished in shorter or longer durations by increasing or decreasing the available resources, such as manpower and equipment [4].

The assumption of controllable processing times acquires great importance when looking at the completion time of the project. A good choice of the amount of resources to be assigned to a task before it starts becomes essential since changing the amount of resources during the execution of the task is detrimental both for the makespan of the task [5] and for its cost [6]. Furthermore, the amount of allocated resources becomes important as a factor which affects productivity (see, e.g., [7]). The current economic crisis emphasizes this fact [8], which is being used by companies to reduce expenses, to optimize their processes, and to adjust their production resources.

Note that, properly speaking, resource-dependent processing times have been usually classified depending on the level of skill of the assigned resources and on the amount of resources. In the former case, a task is performed by a resource (typically an employee) with a given level of skill or experience, and the processing times of that task are different depending on such level (examples can be found in [913]). In the latter case, the processing time of a task changes with the amount of resources assigned to the task. The term "controllable processing times" has traditionally been used in the literature to reflect this case. This paper focuses on this second type. Regarding the type of resources, the classical classification of resources proposed by $[14,15]$ is adopted here whereas resources are classified from the viewpoint of renewability and divisibility. 
With respect to renewability, we note the following.

(i) A resource is denoted as renewable if only its total usage is constrained at every moment; that is, once a resource has been used by a task, it may be assigned to another task.

(ii) A resource is denoted as nonrenewable if its total consumption is constrained; that is, once it is consumed, it cannot be allocated to another task.

(iii) A resource is denoted as doubly constrained if both previous aspects are considered.

With respect to the divisibility, we consider the following.

(i) A resource is called discrete if it can be allocated to the tasks in discrete amounts; that is, we have a finite set of resources.

(ii) A resource is denoted to be continuous if it can be assigned to the tasks in a continuous amount within an interval.

Controllable processing times have been widely analyzed in the scheduling literature (see reviews in $[4,16]$ ). Additionally, there are contributions in related decision problems such as resource allocation or software development size team. Processing times depending on the amount of resources have been used both in production and in project management, for example, for single-machine/flow shop scheduling, resource allocation problems, and multimode resource-constrained project scheduling problem (MRCPSP), and both for discrete and for continuous resources. However, to the best of our knowledge, there is no analysis or detailed discussion regarding the different types of relations between processing times and the amount of resources used in controllable processing times based scheduling problems.

In this paper, the main contributions regarding processing times and the amount of resources used in both production and project management are analyzed. Several properties are defined with the aim of analyzing the relations between processing times and the amount of resources. Some inconsistencies and difficulties to implement the relations, due to infeasible configurations, complexities of the relations, nonlinearities, and so forth, are identified and discussed. More specifically, the remainder of the paper is as follows. A general notation for the controllable processing times is defined in Section 2, along with the theoretical concepts and the basic properties for the relations. The main relations between processing times and the amount of resources found in the literature are analyzed in Section 3. Finally, in Section 4 the conclusions are described.

\section{Notation and Basic Properties}

Since this paper presents results from different research fields, it is necessary to first clarify the notation to be used here. We have tried to accommodate the terms while maintaining the original notation as far as possible.

Let us assume a project (in production management this term is usually denoted as job) composed of several tasks (operations in production management) that have to be performed using an amount of resources $u$. Depending on $u, p$ the processing time of the task may change; that is, $p=p(u)$. Note that the term "project" can be also used instead of "task" when the project is not divided in tasks (e.g., $[17,19,90,92])$. Additionally, let us define the effort, $e=e(u)$, as the amount of man-hours or man-months (depending on the unit of $p$ ) that a task needs to be carried out.

Let us now define $S$ as the size of the task or workload, which indicates the amount of work that has to be performed to complete the task. $S$ is measured in the unit of the work, for example, source lines of codes or function points (FP) for a software task. It is an attribute of each task that will be assumed constant in this paper. Thus, the productivity of the task, $P r$, can be written as a function of the size of the task and the effort (see, e.g., [93-96]):

$$
\operatorname{Pr}=\frac{S}{e(u)}=\operatorname{Pr}(u) .
$$

An increase in the productivity indicates an increase in the task size if the effort is constant or a decrease in the effort when the size of the task remains the same. As it can be seen in (1), the productivity only depends on the amount of resources, $u$. The amount of resources for which the maximum productivity, $\max (P r)$, is achieved is denoted as $u^{*}$ and can be obtained by maximizing the productivity or minimizing the effort. More specifically, we intend to find $u^{*}$ for which $\operatorname{Pr}\left(u^{*}\right) \geq \operatorname{Pr}(u) \forall u \neq u^{*}$. Since $S$ is assumed constant, it is clear that $e\left(u^{*}\right) \leq e(u) \forall u \neq u^{*}$.

The tuple $\left(u^{*}, p\left(u^{*}\right)\right)$, with maximum productivity, is denoted as the productive configuration or productive points of the problem. This approach is implicitly used in several papers related to software projects management. An example can be found in [17] where the minimal effort is sought in order to determine the most productive relation between processing times and amount of resources.

Next, we present two basic properties which must hold. By doing so, two regions are distinguished to establish the limits of the area where each configuration $(u, p)$ can take place. Second, a general law for productive processes is introduced in order to analyze the relations.

Property 1. Assuming that the same amount of resources is available for each period, the processing time of the task must fulfill $p \geq$ constant $/ u$; that is, the processing time must be over an ideal boundary which corresponds to an inverse proportional relation between $p$ and $u$ as defined in Figure 1 .

Proof. If the same amount of resources is employed throughout the duration of the task, the effort can be written as the amount of resources times the processing time of the task (2):

$$
e=p(u) \cdot u
$$

Substituting in the expression (1):

$$
\operatorname{Pr}(u)=\frac{S}{p(u) \cdot u} .
$$




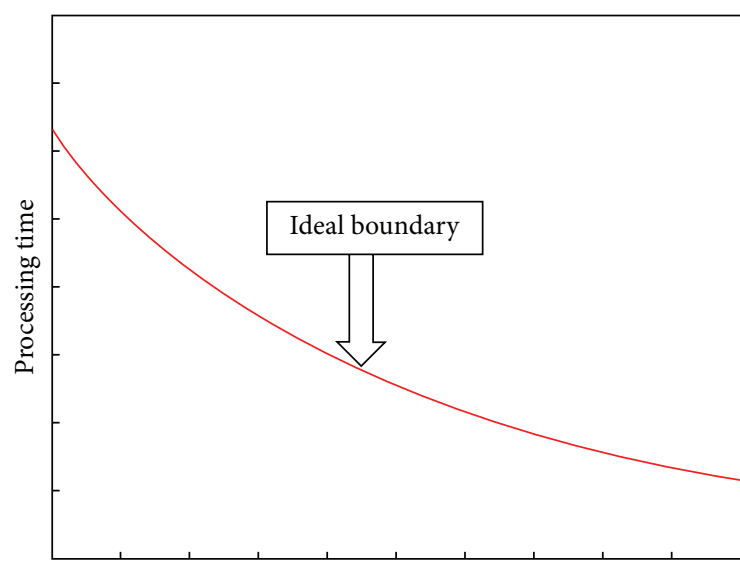

Number of resources

FIGURE 1: Ideal boundary.

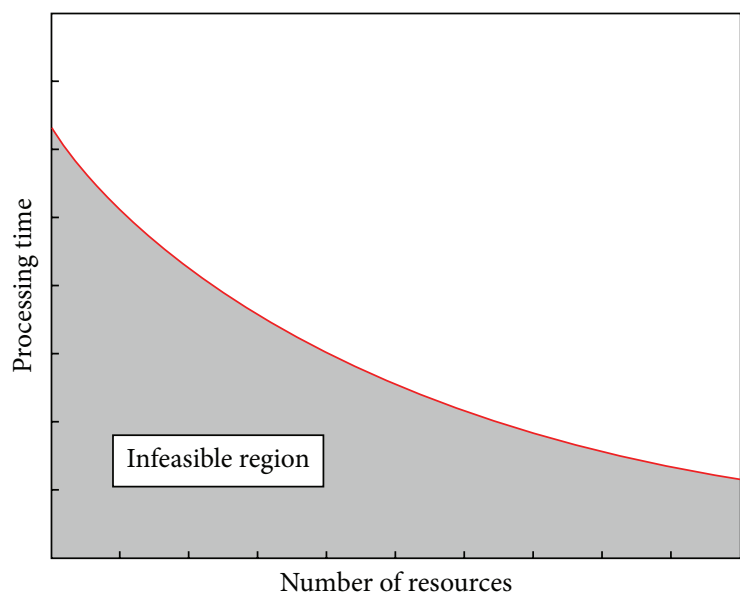

FIgURE 2: Infeasible region.

As shown in (1), maximizing the productivity is equivalent to minimizing the effort; therefore,

$$
\frac{\partial(p(u) \cdot u)}{\partial u}=0=u \cdot \frac{\partial p(u)}{\partial u}+p(u) \longrightarrow \frac{\partial p(u)}{\partial u}=-\frac{p(u)}{u} .
$$

Thus, solving the differential equation, the point $(u, p)$ reaching the maximal productivity is

$$
p(u)=\frac{k}{u} .
$$

Corollary 1. Each tuple $(u, p)$ under the ideal boundary, $p(u) \leq k / u$, is infeasible (see Figure 2); otherwise, $p(u) \geq k / u$ is feasible.

Proof. The proof is trivial in view of Property 1.

Corollary 1 has been implicitly applied by $[46,47]$ and implies that each tuple $(u, p)$ in the region over the curve

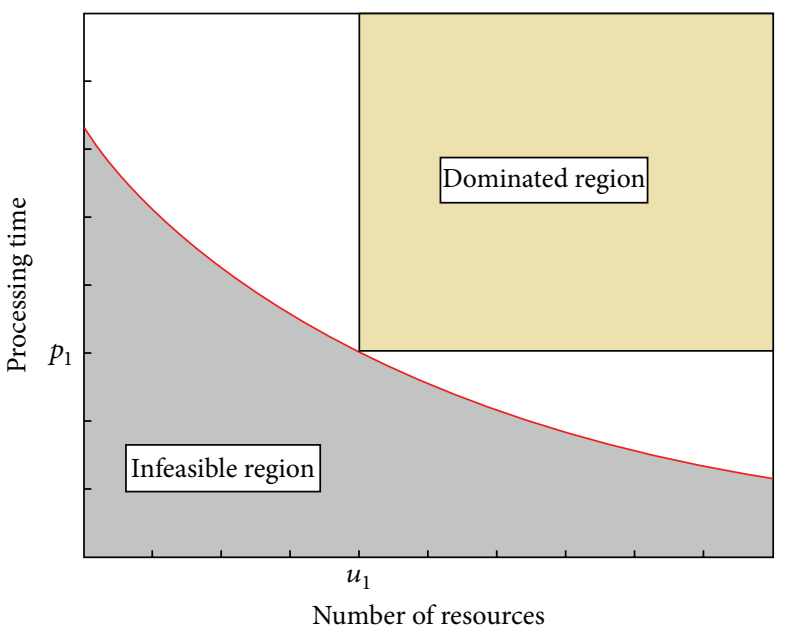

Figure 3: Dominated region.

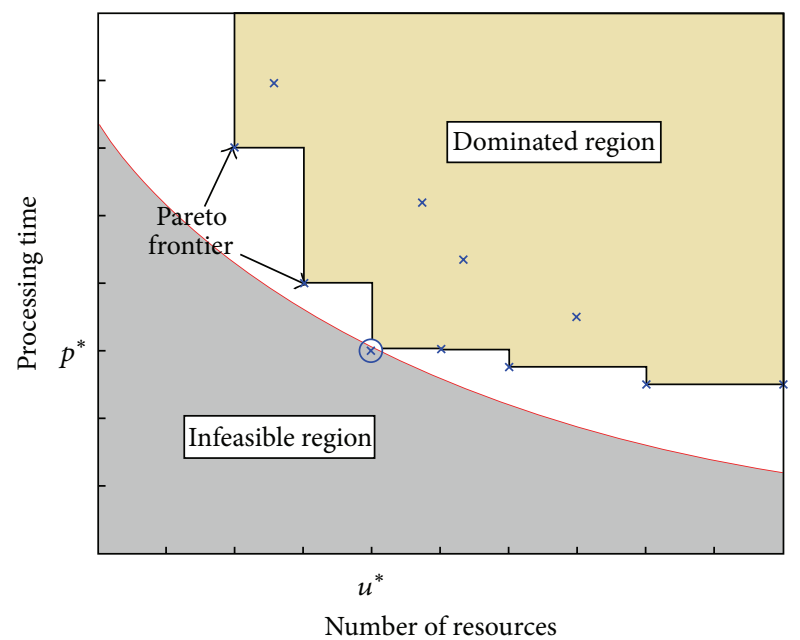

FIgURE 4: Example for many configurations $p-u$.

is feasible. Nevertheless, for a tuple $\left(u_{1}, p_{1}\right)$ in the ideal boundary, any other tuple $(u, p)$ placed in the region "dominated region" (in Figure 3 ) is dominated by $\left(u_{1}, p_{1}\right)$, since the latter achieves less processing times with less amount of resources. Note that points that are nondominated by others are labelled as "efficient" according to the discussion shown in, for example, $[46,97]$. Hence, any tuple $(u, p)$ candidate to be chosen as configuration of the problem must be located outside both the infeasible region and the dominated region, as we can see in Figure 4. In general, at least one tuple with minimal $u \cdot p$ must exist representing the most productive configuration to perform the task, that is, the productive configuration $\left(u^{*}, p\left(u^{*}\right)\right)$. In the following sections, it will be assumed that productive points exist (even if they may be unknown) to have a reference so the different approaches can be compared. Since the goal pursued by companies is to minimize both the processing times and the amount of resources, different trade-offs can be established, which leads to a number of nondominated solutions forming a Pareto frontier. Note that the points over this frontier are dominated 
and cannot be considered as possible configurations for the task; that is, nondominated processing times must be a nonincreasing function of the amount of resources assigned to the task, $d p(u) / d u \leq 0$ for each $u \in[\underline{u}, \bar{u}]$.

Property 2. Given some amount of resources $u^{\prime}$, the fulfillment of the law of diminishing marginal returns is the same as the fulfillment of $(d(1 / p(u)) / d u)\left(u_{2}\right)<(d(1 / p(u)) /$ $d u)\left(u_{1}\right) \forall u_{2}>u_{1}>u^{\prime}$.

Proof. The law of diminishing marginal returns establishes that, given some amount of resources denoted as $u^{\prime}$, the output of a productive process increases at a decreasing rate when the amount of recourse increases (see [98-100]). Considering the output $Y=S / p(u)$ as the amount of the task size performed in each time period and the input $X=u$, the law of diminishing marginal returns can be written as

$$
\begin{array}{r}
Y\left(X_{2}\right)>Y\left(X_{1}\right), \quad \frac{d Y}{d X}\left(X_{2}\right)<\frac{d Y}{d X}\left(X_{1}\right), \\
\forall X_{2}>X_{1}>X^{\prime} .
\end{array}
$$

Substituting $Y$ and $X$ in expression (6),

$$
\begin{array}{r}
\frac{d(S / p(u))}{d u}\left(u_{2}\right)<\frac{d(S / p(u))}{d u}\left(u_{1}\right) \\
\longrightarrow \frac{d(1 / p(u))}{d u}\left(u_{2}\right)<\frac{d(1 / p(u))}{d u}\left(u_{1}\right) \\
\forall u_{2}>u_{1}>u^{\prime}
\end{array}
$$

Corollary 2. Given some amount of resources, $u^{\prime}$, the processing times of the task must satisfy $d^{2}(1 / p(u)) / d u^{2}<0 \forall u^{\prime}<$ $u<\bar{u}$.

Proof. The proof is trivial in view of Property 2.

This property, together with the previous one, is used in this paper to analyze the different relations used in production management. Although in production management the output must satisfy the law of diminishing marginal returns, there is no such condition in project management. However, there are several results based on the experimentation for renewable discrete resource (manpower) in the literature. Among them, [101] established that the $u$-productivity graphics must be similar to an inverted U-shape where it is assumed that there is only a single productive configuration with maximum productivity defined by the tuple $\left(u^{*}, p\left(u^{*}\right)\right)$ [102]. The productivity decreases for $u>u^{*}$; this scenario is denoted as EC in the following, due to the fact that there is too much coordination and communication if more employees are assigned $[92,103]$ and that these difficulties in communication increase with the size of the team $[7,104]$. It is also assumed that there is a decrease in productivity due to lack of specialization, denoted as LS, in small teams if fewer employees are assigned (i.e., for $u<u^{*}$ ). This fact is confirmed by [105], who also cite other difficulties such as making trade-off decisions or managing error backlog.
As a summary, a number of properties have been presented in this section. These will be discussed in the next sections.

\section{Analysis of the Main Relations in the Literature}

The main relations between processing times and amount of resources are presented and classified in this section. This section takes into account relations used in production and project management since most of them (except 3) have been used interchangeably. The environment where each relation is used is indicated within brackets after the title of the relation. The goal is to analyze how processing times depending on the amount of resources have been treated in the literature and to discuss their use. A detailed summary of the papers using processing times as a function of the amount of resources presented here can be seen in Table 1, and a summary of the section is shown in Section 3.6.

3.1. Linear Relation (Production and Project Management). Although the majority of scheduling problems in the literature consider fixed processing times $[3,65]$, different relations between $p$ and $u$ have been also assumed for scheduling problems and for decision problems. According to [16], most papers using controllable processing times assume a linear relation between processing times and the amount of resources. For instance $[8,25,65-80]$, consider for the singlemachine scheduling ([81] in a two-agent scheduling problem) that processing times can increase or decrease within a lower and upper bound ( $p$ and $\bar{p}$, resp.) depending linearly on the nonrenewable resoürces (cost) assigned. This single-machine problem is also solved considering discrete processing times by [78]. The linear approach for renewable and nonrenewable continuous resources is considered for a single-machine by [85] and by [86] for the hybrid flow shop problem. For discrete resources, the linear approach is assumed by $[83,84]$ for the single-machine and by [82] for flow shop scheduling. Both discrete and continuous resources are considered in single-machine problems by [87] for renewable resources and for renewable and nonrenewable resources by [26, 58-62] and by [60] for parallel-machine scheduling. Learning effect is added to the linear relations in $[33-35,63]$ without changing the linearity of the relation between $p$ and $u$.

In the area of project management, there are few papers using this relation. See, for example, [19] which includes this assumption in a multiple project scheduling using renewable resources.

Traditionally, most problems considering controllable processing times have used the following relation (e.g., [16, 34, 84]):

$$
p(u)=\bar{p}-b \cdot u \quad \text { with } \underline{u} \leq u \leq \bar{u},
$$

where $\underline{u}$ and $\bar{u}$ are, respectively, the lower (typically 0 ) and upper bound for $u \cdot \bar{p}$ and $b$ are constants referring to the basic processing times (also denoted normal or nominal processing time) and to the compression rate of the task, which identifies the slope of the line. The linear expression could be also 


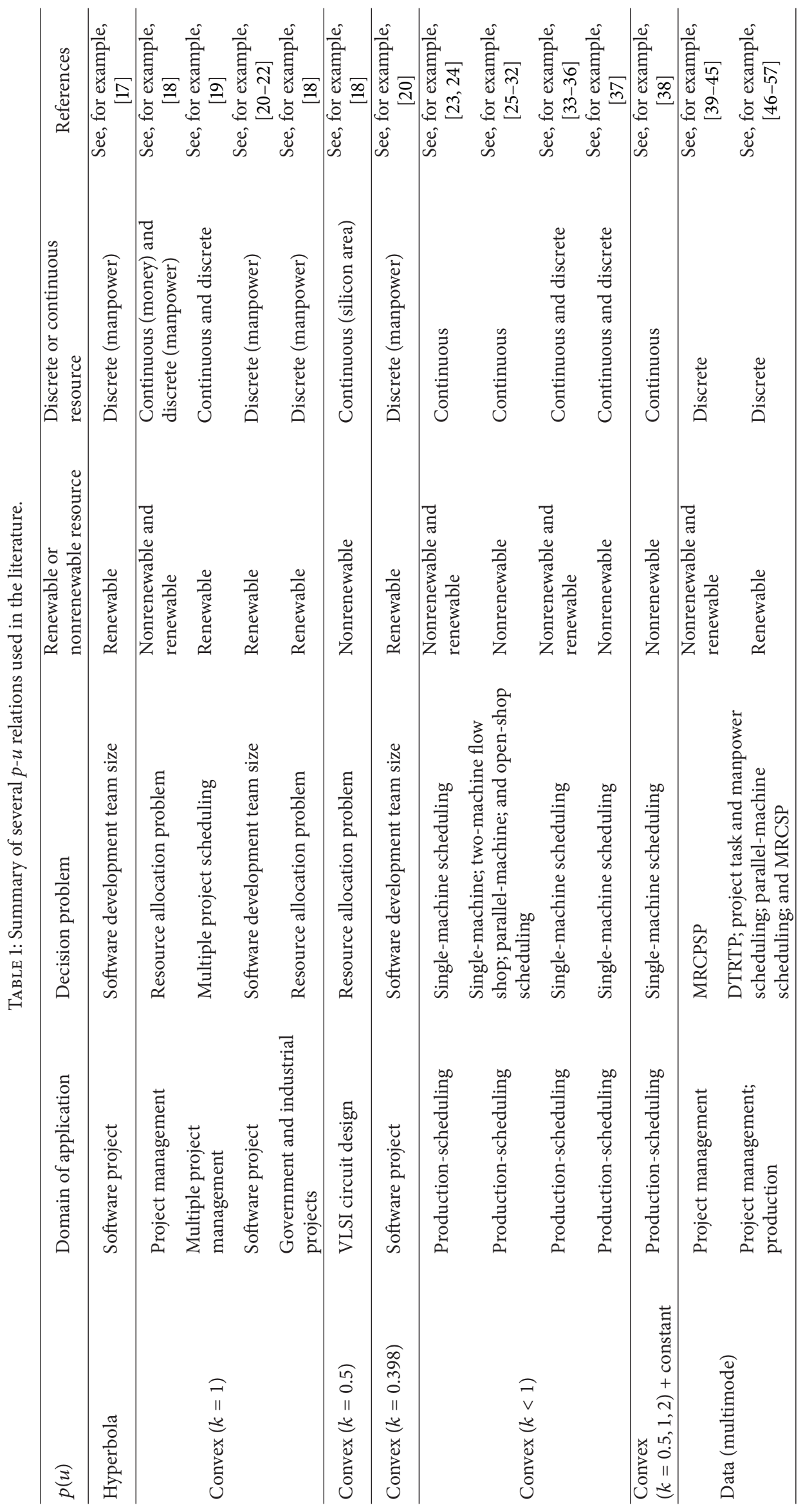




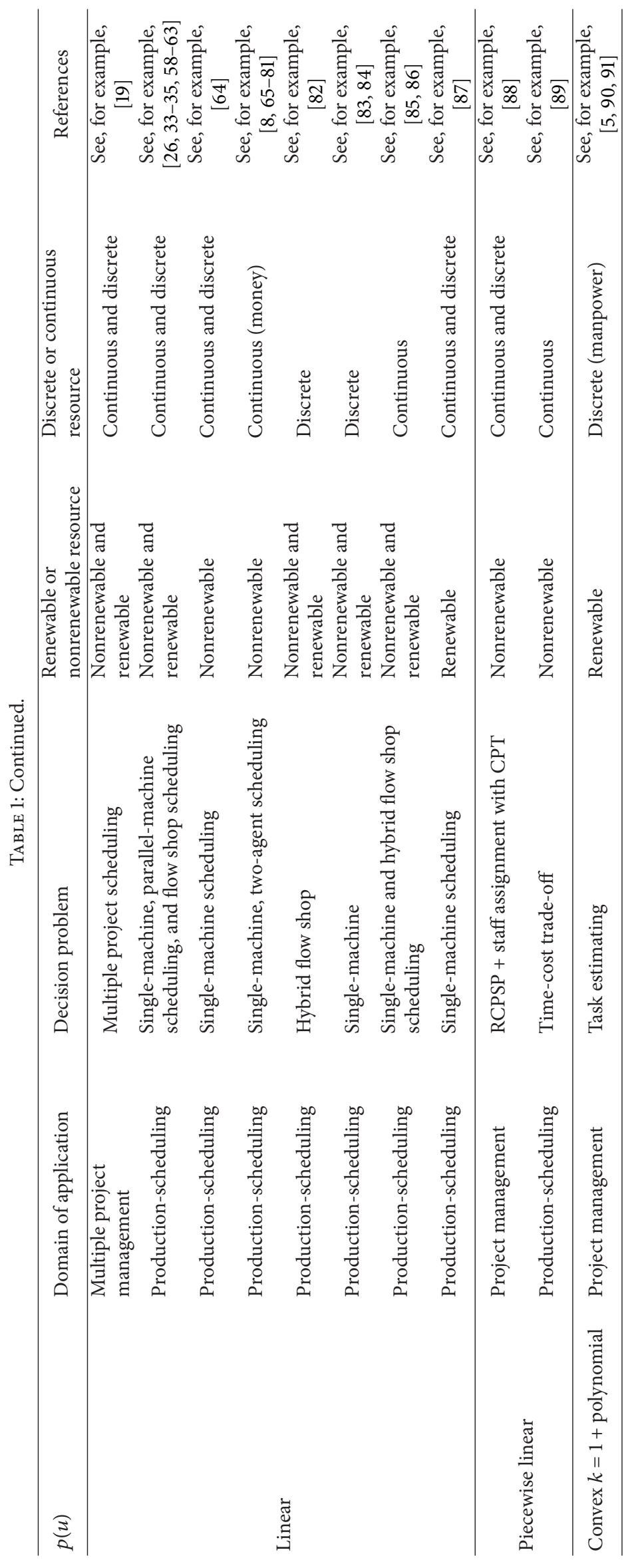


expressed in function of some tuple $\left(u_{1}, p_{1}\right)$ instead of $b$; that is,

$$
\begin{gathered}
p_{1}=\bar{p}-b \cdot u_{1} \longrightarrow b=\frac{\bar{p}-p_{1}}{u_{1}}, \\
p(u)=\bar{p}+\frac{\bar{p}-p_{1}}{u_{1}} \cdot u .
\end{gathered}
$$

The expression of the productivity as a function of the team size is, according to Section 2, the following:

$$
\operatorname{Pr}=\frac{S}{[\bar{p}-b \cdot u] \cdot u} .
$$

If $\bar{p}$ and $b$ are known and fixed, the productivity only depends on the number of resources assigned to the task. Obviously, the tuple with maximum productivity $\left(u^{*}, p\left(u^{*}\right)\right)$ must be in one of the two endpoints (see Figure 5).

Regarding the fulfillment of the law of diminishing marginal returns, this can be easily checked by Property 2 deriving the inverse of the processing time with $u_{1}<u_{2}$ :

$$
\begin{aligned}
& \frac{d(1 / p(u))}{d u}\left(u_{2}\right)<\frac{d(1 / p(u))}{d u}\left(u_{1}\right) \\
& \longrightarrow \frac{d(1 /(\bar{p}-b \cdot u))}{d u}\left(u_{2}\right)<\frac{d(1 /(\bar{p}-b \cdot u))}{d u}\left(u_{1}\right) \\
& \longrightarrow \frac{b}{\left(\bar{p}-b \cdot u_{2}\right)^{2}}<\frac{b}{\left(\bar{p}-b \cdot u_{1}\right)^{2}} \\
& \rightarrow\left(\bar{p}-b \cdot u_{1}\right)^{2}<\left(\bar{p}-b \cdot u_{2}\right)^{2} .
\end{aligned}
$$

Since processing times must be positive $(\bar{p}-b \cdot u>0)$, the expression can be written as

$$
\bar{p}-b \cdot u_{1}<\bar{p}-b \cdot u_{2} \longrightarrow u_{2}<u_{1}
$$

which is not possible.

Hence, the linear relation does not satisfy the law of diminishing marginal returns for any amount of resources and it can be only employed as an approximation of $p(u)$. Note that, when using this configuration, only a productive point typically exists, and it is placed in the most productive endpoint, $\underline{u}$ or $\bar{u}$. If both endpoints are equally productive, two productive points exist. Additionally, the linear relation does not realistically model the processing time of a task since the task could be performed even if no resource is assigned and in a zero time if a large amount of resources is allocated. The widespread use of the linear relation is probably due to its simplicity and as an approximation of the convex relation with $k<1$ and $k=1$ (see Sections 3.3.1 and 3.3.2), which is valid only for small intervals.

As mentioned before, this relation has been mostly used for production management. Nevertheless there are also references in project management (see, e.g., [19]). For this relation, the $u$-productivity graphic is not similar to an inverted U-shape (see Figure 5). In fact, it is more similar to the opposite figure, a U-shape. Thereby, in project management, this relation could be only used to model an approximation of the lack of specialization or of the excess of communication but never to model both effects since the productive points are always in the endpoints.

3.2. Piecewise Linear (Production and Project Management). A piecewise linear decreasing relation between processing times and the amount of nonrenewable continuous resources assigned to the task is proposed by [89] in production and by [88] in project management. In the former, this relation is adjusted to the convex curve with $k=1$ by setting some points of the piecewise linear relation over the convex curve (see an example in Figure 6). The goal of this relation is to linearize the convex expression and to facilitate the construction of an integer linear programming model to solve the decision problem (the same idea could be extended to represent other behaviors of the task, such as a convex relation with $k=0.5$, by changing the chosen points for other points in the new curve). As with the convex relation (see Section 3.3.1), using this approach, the piecewise linear relation would not satisfy the law of the diminishing returns since it is formed by several lines that do not satisfy this law (see Section 3.1). In the latter, a piecewise linear relationship with two sections is proposed to approximate the behavior of the $u$ productivity to an inverted U-shape where the productive configuration is the point between both sections.

\subsection{Convex Relation (Production and Project Management).} The general expression used for this case is

$$
p=\left(\frac{d}{u}\right)^{k}
$$

where $d$ is a constant usually denoted as workload and $k$ is a positive constant which holds 1 for many actual government and industrial projects [18], distributed communication network, time-sharing computing system, chemical plant, or commercial construction projects [19], while $k=0.5$ has been used in many large scale integration (VLSI) circuit designs where the resource is silicon area [18].

In production management, a convex relation between processing times and amount of nonrenewable continuous resources with a generic $k$ has been used, for example, by [25-31] in single-machine, two-machine, parallel-machine, and open-shop scheduling problems. Renewable resources are assumed by several authors (see, e.g., [23, 24]) also for the single-machine scheduling problem. Continuous and discrete nonrenewable resources are considered, for example, by [37] for the single-machine scheduling problem with deteriorating jobs. Examples of papers using the convex relation in a single-machine scheduling problem with learning effect taking into account any type of resource can be found in [3336]. Both learning effect and deteriorating jobs do not change the convex relation between $p$ and $u$.

In contrast with the linear relation, this convex relation seems to fit better into the aforementioned real problems. Additionally, only one parameter has to be calculated to implement it as compared to the 2 parameters needed by the 

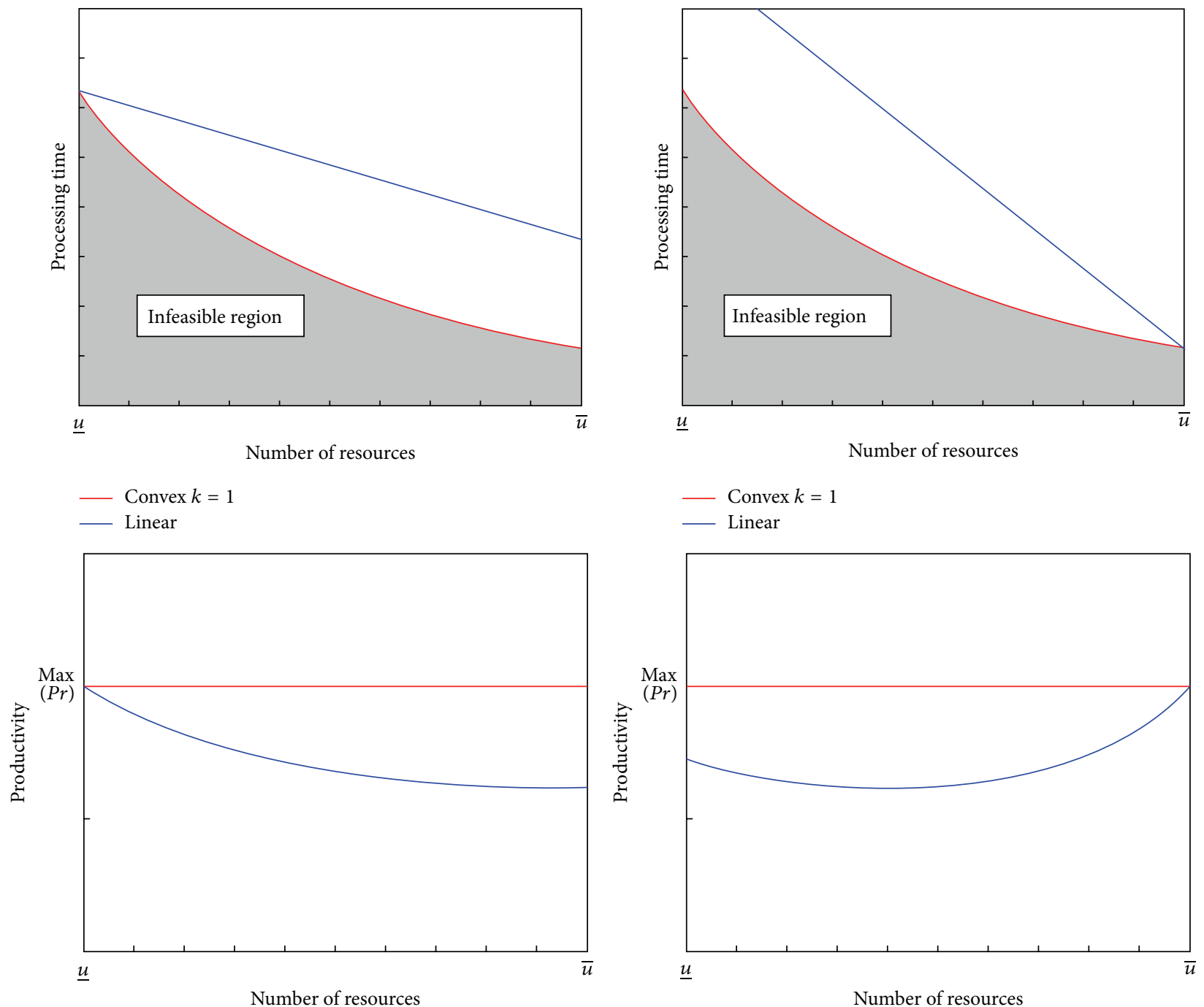

FIgURe 5: Processing times and productivities for linear relation.
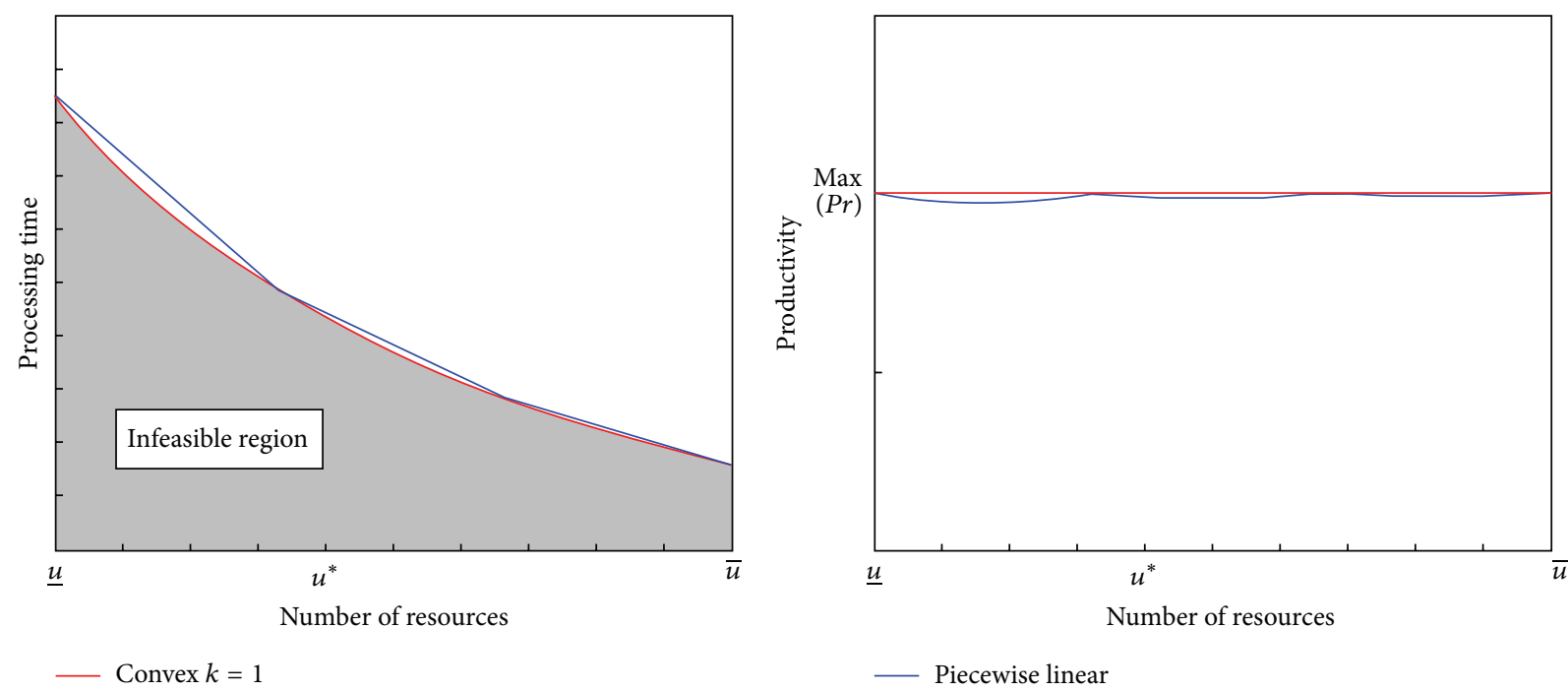

Convex $k=1$

— Piecewise linear

Figure 6: Piecewise linear relation. 
linear relation. However, its nonlinearity makes modeling the decision problems using linear programming difficult.

Despite the aforementioned shortcomings, many papers in the literature justify this relation with the argument that the linear relation does not obey the law of diminishing marginal returns, whereas the convex relation does (see, e.g., $[3,18,23$, 27]). In our opinion, this argument must not be further used as justification of the use of the convex relation, according to the findings in this section.

3.3.1. Convex Relation with $k=1$ (Production and Project Management). Here, there is an inversely proportional relation between the processing times and the amount of resources assigned [27]:

$$
p=\frac{d}{u} \longrightarrow p \cdot u=e=d
$$

where $d$, usually denoted as workload, is a constant and, consequently, the effort is also a constant for this relation. In Section 2, it was shown that any point in this relation is within the ideal boundary and the constant $d$ can therefore be calculated considering that the curve cuts one of these points $\left(u_{1}, p_{1}\right)$ :

$$
p_{1}=\frac{d}{u_{1}} \longrightarrow d=u_{1} \cdot p_{1}
$$

Substituting in (14), the convex relation with $k=1$ can be obtained:

$$
p=\frac{u_{1} \cdot p_{1}}{u}
$$

When no relation between $p$ and $u$ is known, the constant $d$ has been also calculated in the literature using the workload, $S$, or a function of it (see [20-22]), $f(S)$. As mentioned in Section 2, the relation between $p$ and $u$ corresponds to the ideal boundary whose points have maximum productivity.

Accordingly, the convex relation with $k=1$ must be used in the case where each configuration between $p$ and $u$ has the same value of the productivity and, therefore, each point is a productive point. That is, when the amount of resources increases, the processing time decreases in the same proportion. This corresponds with the ideal case both in production and in project management where there are no penalties for employing additional resources. In fact, this relation does not fulfill the law of diminishing returns as the derivate of the output is constant, so it does not decrease:

$$
\begin{aligned}
Y(X) & =Y(u)=\frac{S}{p(u)}=S \cdot u, \\
\frac{d Y}{d X}(X) & =\frac{d(S \cdot u)}{d u}(u)=S \longrightarrow \frac{d Y}{d X}\left(X_{1}\right)=\frac{d Y}{d X}\left(X_{2}\right) .
\end{aligned}
$$

Regarding project management, this relation does not consider penalties due to excess of communication (excess of the number of employees) or lack of specification for manpower since the productivity is constant for any amount of resources.
3.3.2. Convex Relation with $k<1$ (Production and Project Management). The convex relation with $k<1$ is analysed here:

$$
p=\left(\frac{d}{u}\right)^{k}, \quad \text { with } \underline{u} \leq u \leq \bar{u},
$$

where $d$ is a constant which can be defined when a point of the curve is known. Hence, assuming that the curve includes the point $\left(u_{1}, p_{1}\right)$, the constant $d$ can be calculated; that is,

$$
p_{1}=\left(\frac{d}{u_{1}}\right)^{k} \longrightarrow d=u_{1} \cdot\left(p_{1}\right)^{1 / k} .
$$

As with the convex relation with $k=1$, one point is only necessary to completely define the relation, in contrast to relations as the hyperbola (see Section 3.4) that needs to define up to 4 parameters.

Thereby, the relation can be written again in expression (20) using a point in the curve (expression (19)) (for a representation see Figure 7):

$$
p=p_{1} \cdot\left(\frac{u_{1}}{u}\right)^{k}
$$

Substituting in the expression of the productivity:

$$
\operatorname{Pr}=\frac{S}{p \cdot u}=\frac{S}{p_{1} \cdot\left(u_{1} / u\right)^{k} \cdot u}=\frac{S}{p_{1} \cdot u_{1}^{k} \cdot u^{1-k}}=\frac{\text { constant }}{u^{1-k}} .
$$

As we can see in expression (21) or in Figure 7, the productivity always increases by assigning fewer resources to the task for $k<1$. This can be easily seen using expression (21):

$$
\begin{aligned}
u_{1} & <u_{2} \longrightarrow \frac{1}{u_{1}}>\frac{1}{u_{2}} \longrightarrow\left(\frac{1}{u_{1}}\right)^{1-k}>\left(\frac{1}{u_{2}}\right)^{1-k} \\
& \longrightarrow P r_{1}>P r_{2} .
\end{aligned}
$$

Hence, this relation within $p-u$ corresponds to tasks whose maximum productivity (productive configuration) is in $\underline{u}$ resources $\left(u^{*}=\underline{u}\right)$, and this productivity decreases with the increase of resources assigned. The law of diminishing marginal returns is fulfilled as it can be seen in (23) using Property 2 for the point $u^{\prime}=0$ :

$$
\begin{aligned}
& \frac{d(1 / p(u))}{d u}\left(u_{2}\right)<\frac{d(1 / p(u))}{d u}\left(u_{1}\right) \\
& \longrightarrow \frac{d\left((u / d)^{k}\right)}{d u}\left(u_{2}\right)<\frac{d\left((u / d)^{k}\right)}{d u}\left(u_{1}\right) \\
& \longrightarrow \frac{k \cdot u_{2}^{k-1}}{d^{k}}<\frac{k \cdot u_{1}^{k-1}}{d^{k}} \\
& \longrightarrow u_{2}{ }^{k-1}<u_{1}{ }^{k-1} \stackrel{k<1}{\longrightarrow} u_{1}<u_{2} .
\end{aligned}
$$

This expression is satisfied for any amount of resources from the left endpoint $\left(u^{\prime}=0\right)$. However, the law of the 

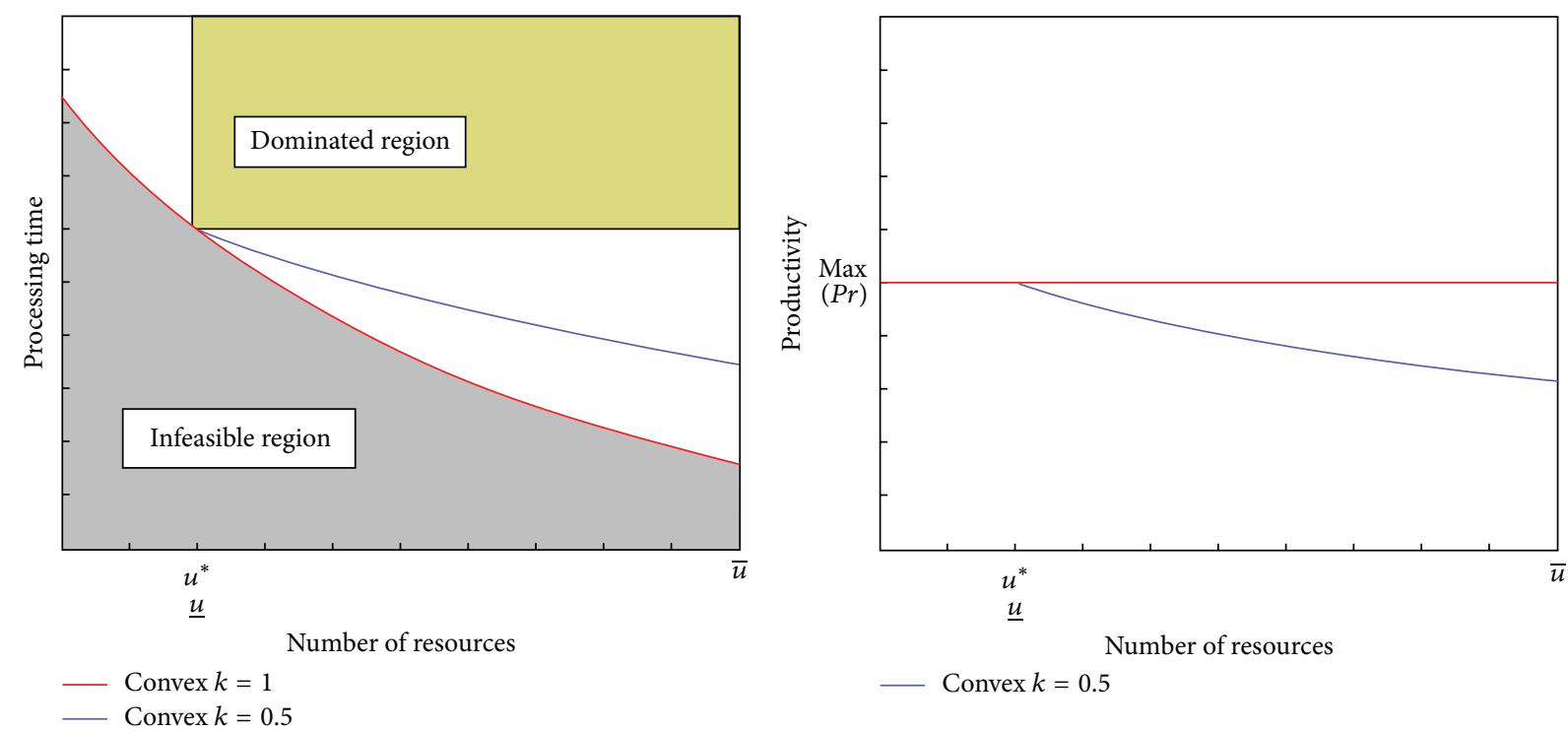

FIGURE 7: Graphic for convex relation with $k=0.5$.

diminishing marginal returns establishes that the point $u^{\prime}$ must not necessarily be the initial point, $u^{\prime}=0$, and the output of the system can increase with an increasing rate at the beginning of the process [98-100]. Thus, this relation has to be used for processes which always increase at a decreasing rate.

According to the project management literature, this relation considers the penalty due to the excess of communication when more employees are assigned to the task where it is assumed that the productive point is achieved with the minimal amount $\underline{u}$ of resources; that is, this model does not include any penalty due to the lack of specialization and any inverted U-shape for the productivity.

3.3.3. Convex Relation with $k+$ Constant (Production). Convex relation plus a constant is introduced by [38] for a singlemachine scheduling problem using expression (24), where $b$ and $d$ are constants denoting constant processing times and workload, respectively. Both $b$ and $d$ can be defined if two points of the curve are known. The three values for parameter $k$ in the literature have been tested here: $0.5,1$, and 2 , obtaining different results than for the convex relation with $k$ without constant. These values are discussed in the next sections. Consider

$$
p=b+\left(\frac{d}{u}\right)^{k} \quad \text { with } \underline{u} \leq u \leq \bar{u} .
$$

(1) Convex Relation with $k=0.5+$ Constant (Production). Consider

$$
p=b+\left(\frac{d}{u}\right)^{0.5}, \quad \text { with } \underline{u} \leq u \leq \bar{u} .
$$

Using expression (25), the productivity can be defined as follows:

$$
\operatorname{Pr}=\frac{S}{p \cdot u}=\frac{S}{\left[b+(d / u)^{0.5}\right] \cdot u}=\frac{S}{b \cdot u+d^{0.5} \cdot u^{0.5}} .
$$

As for the convex relation with $k<1$ (Section 3.3.2), the productivity always decreases with $u$ and the productive point is the left endpoint, $\underline{u}$, that can be found by minimizing the denominator of the productivity:

$$
\begin{aligned}
& \frac{d\left(b \cdot u+d^{0.5} \cdot u^{0.5}\right)}{d u}=b+\frac{0.5 \cdot d^{0.5}}{u^{0.5}}=0 \\
& \longrightarrow u^{*}<0 \longrightarrow u^{*}=\underline{u} .
\end{aligned}
$$

The law of diminishing marginal returns is fulfilled for any amount of resources $\left(u^{\prime}=0\right)$ (see (28) using Corollary 2):

$$
\begin{aligned}
& \frac{d^{2}(1 / p(u))}{d u^{2}}<0 \\
& \quad \longrightarrow \frac{d(1 / p(u))}{d u}=\frac{d\left(u^{0.5} /\left(u^{0.5} \cdot b+d^{0.5}\right)\right)}{d u} \\
& \frac{d(1 / p(u))}{d u} \\
& =\frac{0.5 \cdot u^{-0.5} \cdot\left(u^{0.5} \cdot b+d^{0.5}\right)-u^{0.5} \cdot 0.5 \cdot b \cdot u^{-0.5}}{\left(u^{0.5} \cdot b+d^{0.5}\right)^{2}} \\
& =\frac{0.5 \cdot u^{-0.5} \cdot d^{0.5}}{\left(u^{0.5} \cdot b+d^{0.5}\right)^{2}} \\
& \longrightarrow \frac{d^{2}(1 / p(u))}{d u^{2}} \\
& \quad \frac{-0.5^{2} \cdot d^{0.5} \cdot u^{-1.5} \cdot\left(u^{0.5} \cdot b+d^{0.5}\right)-0.5 \cdot u^{-1} \cdot d^{0.5} \cdot b}{\left(u^{0.5} \cdot b+d^{0.5}\right)^{3}} \\
& <0
\end{aligned}
$$




$$
\begin{aligned}
& \longrightarrow \frac{-0.5^{2} \cdot d \cdot u^{-1.5}-0.75 \cdot d^{0.5} \cdot b \cdot u^{-1}}{\left(u^{0.5} \cdot b+d^{0.5}\right)^{3}}<0 \\
& \longrightarrow \text { Fulfilled } \longrightarrow u^{\prime}=0 .
\end{aligned}
$$

Both productivity curve and the relation between processing time and amount of resources are shown in Figure 8. Note that the same results as in Section 3.3.2 have been found for the convex relation with $k<1$. The sum of the constants does not influence the conclusions of such relation stated before.

(2) Convex Relation with $k=1+$ Constant (Production). Consider

$$
p=b+\frac{d}{u}, \quad \text { with } \underline{u} \leq u \leq \bar{u} .
$$

An example of this relation can be found in Figure 9. Using expression (29), the productivity can be defined as follows:

$$
\operatorname{Pr}=\frac{S}{p \cdot u}=\frac{S}{[b+d / u] \cdot u}=\frac{S}{b \cdot u+d} .
$$

It can be easily shown that the productivity decreases with the amount of resources (see Figure 9) and, hence, the amount of resources which maximizes the productivity is $u^{*}=\underline{u}$.

The law of diminishing marginal returns is fulfilled for any amount of resources $\left(u^{\prime}=0\right)$, as it can be seen below using Corollary 2:

$$
\begin{aligned}
& \frac{d^{2}(1 / p(u))}{d u^{2}}<0 \\
& \longrightarrow \frac{d(1 / p(u))}{d u}=\frac{d(u /(u \cdot b+d))}{d u}=\frac{(u \cdot b+d)-u \cdot b}{\left(u^{0.5} \cdot b+d\right)^{2}} \\
& \longrightarrow \frac{d(1 / p(u))}{d u}=\frac{d}{(u \cdot b+d)^{2}} \\
& \frac{d^{2}(1 / p(u))}{d u^{2}}=\frac{-2 \cdot d \cdot b}{(u \cdot b+d)^{3}}<0 \\
& \longrightarrow \text { Fulfilled } \longrightarrow u^{\prime}=0 .
\end{aligned}
$$

Note that, in this case, the law of diminishing marginal returns is fulfilled as compared to the convex relation with $k=1$ (Section 3.3.1), where it was not. Additionally, here the productive point is the left endpoint, instead of every point on the curve, and consequently the relation does not correspond to the ideal boundary.

(3) Convex Relation with $k=2+$ Constant (Production). Consider

$$
p=b+\left(\frac{d}{u}\right)^{2}, \quad \text { with } \underline{u} \leq u \leq \bar{u} .
$$

The productivity (33) can be obtained by substituting the expression of processing times (32) in the general expression of productivity (3). Consider

$$
\operatorname{Pr}=\frac{S}{p \cdot u}=\frac{S}{\left[b+(d / u)^{2}\right] \cdot u}=\frac{S}{b \cdot u+d^{2} / u} .
$$

To obtain the amount of resources that maximizes the productivity, we minimize the denominator (33) obtaining point $u^{*}=d / \sqrt{b}$ (see (34) and Figure 10):

$$
\frac{d\left(b \cdot u+d^{2} / u\right)}{d u}=b-\frac{d^{2}}{u^{2}}=0 \longrightarrow u^{*}=\frac{d}{\sqrt{b}} .
$$

The law of diminishing marginal returns is fulfilled for $\left(u^{\prime}=d / \sqrt{3 \cdot b}\right)$ as it can be seen below using Corollary 2; that is, there exists an amount of resources $u^{\prime}$ for which the output of the productive process increases at a decreasing rate:

$$
\begin{aligned}
& \frac{d^{2}(1 / p(u))}{d u^{2}}<0 \\
& \longrightarrow \frac{d(1 / p(u))}{d u}=\frac{d\left(u^{2} /\left(u^{2} \cdot b+d^{2}\right)\right)}{d u} \\
& =\frac{2 \cdot u \cdot\left(u^{2} \cdot b+d^{2}\right)-2 \cdot u^{3} \cdot b}{\left(u^{2} \cdot b+d^{2}\right)^{2}}=\frac{2 \cdot u \cdot d^{2}}{\left(u^{2} \cdot b+d^{2}\right)^{2}} \\
& \frac{d^{2}(1 / p(u))}{d u^{2}} \\
& =\frac{2 \cdot d^{2} \cdot\left(u^{2} \cdot b+d^{2}\right)-2 \cdot u \cdot d^{2} \cdot 4 \cdot u \cdot b}{\left(u^{2} \cdot b+d^{2}\right)^{3}}<0 \\
& \longrightarrow \frac{2 \cdot d^{4}-6 \cdot u^{2} \cdot d^{2} \cdot b}{\left(u^{2} \cdot b+d^{2}\right)^{3}}<0 \\
& \longrightarrow 2 \cdot d^{4}-6 \cdot u^{2} \cdot d^{2} \cdot b<0 \\
& \longrightarrow u^{2}>\frac{d^{2}}{3 \cdot b} \longrightarrow u>\frac{d}{\sqrt{3 \cdot b}} \\
& \longrightarrow u^{\prime}=\frac{d}{\sqrt{3 \cdot b}} .
\end{aligned}
$$

This relation allows us to choose the constants $b$ and $d$ in order to determine the productive amount of resources in contrast with the majority of the relations (with the exception of the hyperbola and multimode) where the productive point is imposed by the relation chosen (typically an endpoint). Note that, for $b=0$, the productive point is in $u^{*} \rightarrow \infty$ and the law of diminishing marginal returns is not fulfilled for any amount of resources ( $u^{\prime}$ being the left endpoint).

3.3.4. Convex + Communication (Project Management). The work of $[5,90,91]$ introduces in the convex approach a penalty due to communication between resources consisting on manpower (i.e., discrete and renewable). This penalty is 


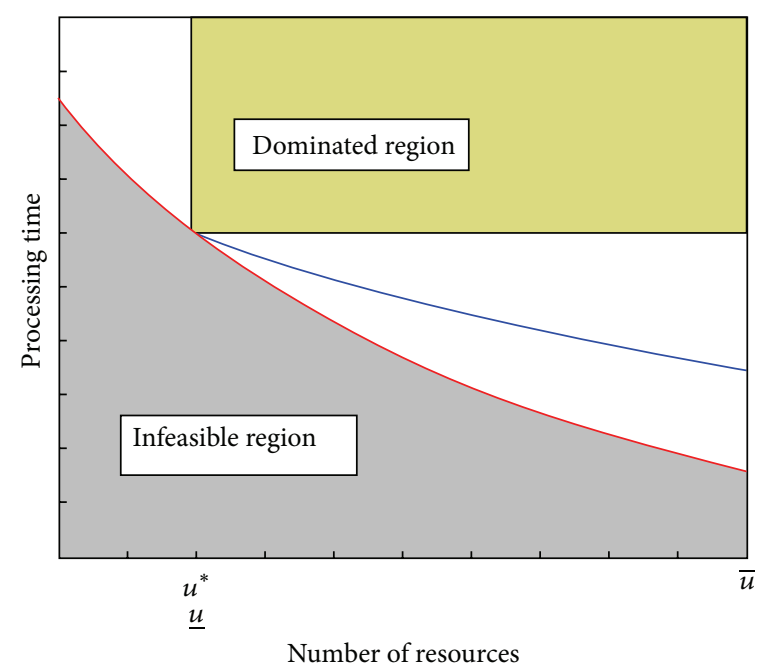

- Convex $k=0.5+$ constant

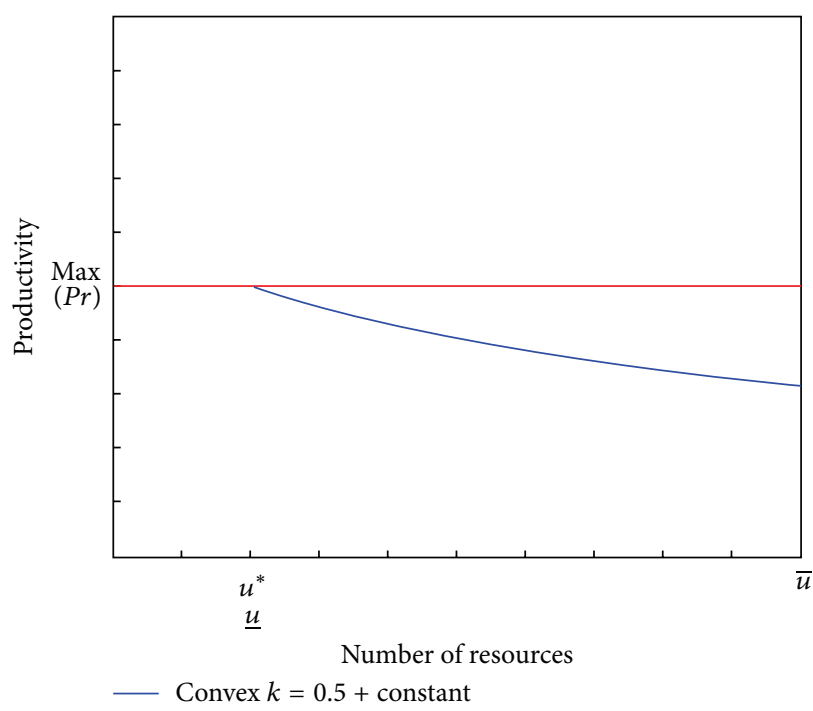

FIgURE 8: Convex relation with $k=0.5+$ constant.
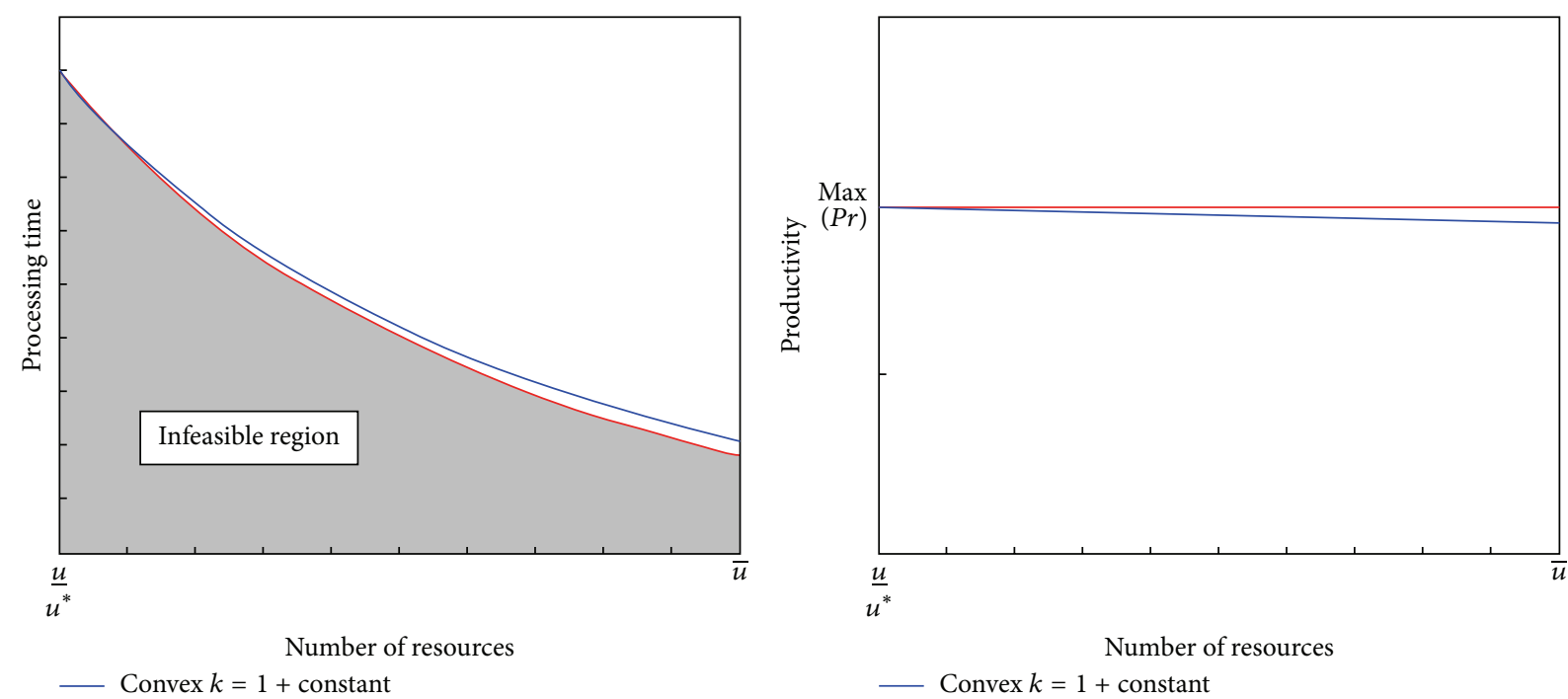

Figure 9: Convex relation with $k=1+$ constant.

considered using a polynomial or even a logarithmic model by these papers. A quadratic function (36) is assumed:

$$
p=\frac{d}{u}+e c \cdot u \cdot(u-1),
$$

where $d$ and $e c$ are constants representing the estimated effort and the average communication effort for a pair of people, respectively. An example of this relation can be seen in Figure 11.

According to the productivity, we have

$$
\begin{aligned}
\operatorname{Pr} & =\frac{S}{p \cdot u} \\
& =\frac{S}{[d / u+e c \cdot u \cdot(u-1)] \cdot u}=\frac{S}{d+e c \cdot u^{2} \cdot(u-1)} .
\end{aligned}
$$

It can be easily checked that the maximum integer nonnegative point of this function is $u=u=u^{*}$ and that the productivity always decreases when more employees are assigned (as in the convex relation with $k<1$ ) since the denominator is a nondecreasing function (see Figure 11). Each point to the right of $u$ is feasible. Additionally, as compared with the convex relation with $k=0.5$, there exists a point from which the relation is dominated by other points (i.e., $d p / d u>0$, see Figure 11) due to the penalty for communication. In addition, it is necessary to determine two parameters, which makes it more difficult to implement this relation as compared to the convex one. Furthermore, this relation does not consider the penalty due to the lack of specialization.

3.4. Hyperbola (Project Management). This relation between $p$ and $u$ was introduced by [17] for discrete renewable resources (manpower). In the linear, convex with $k=0.5$, and 

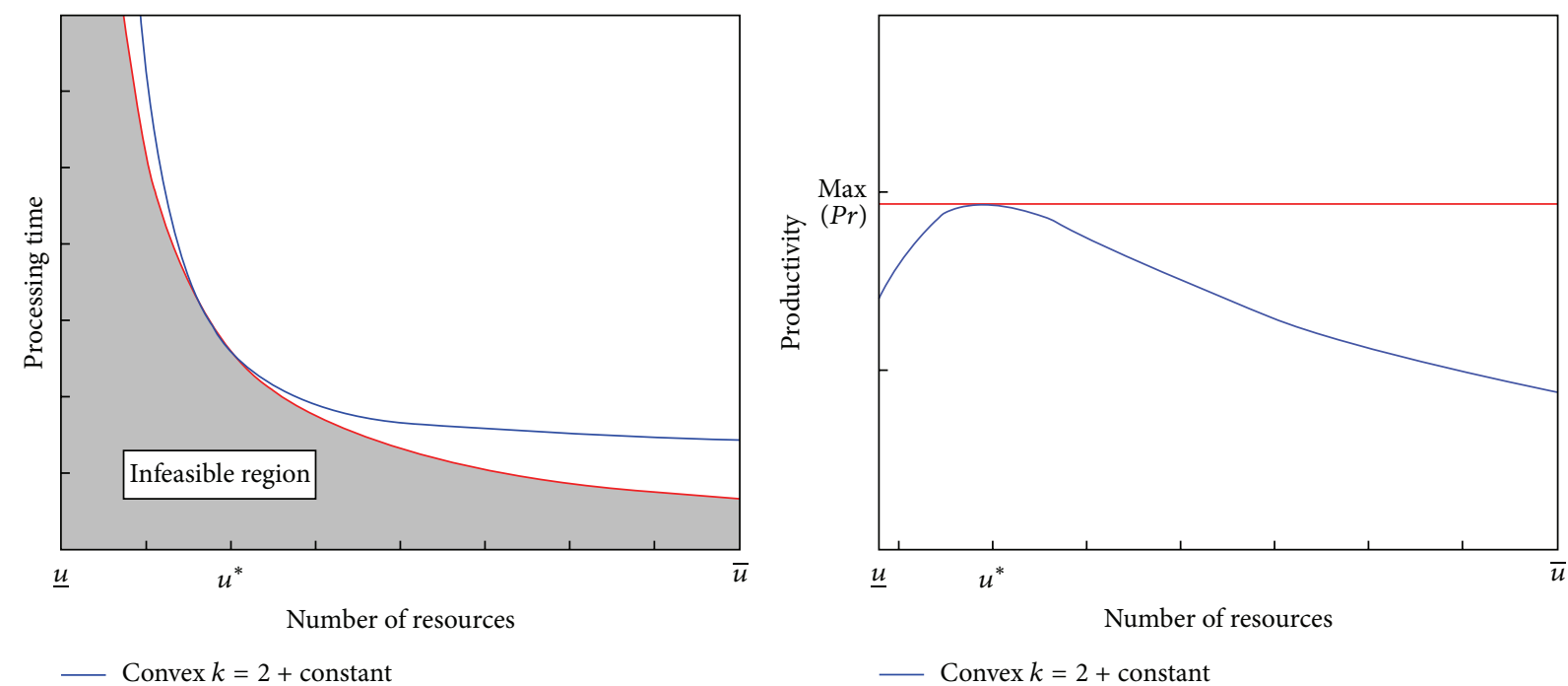

FIgURE 10: Convex relation with $k=2+$ constant.
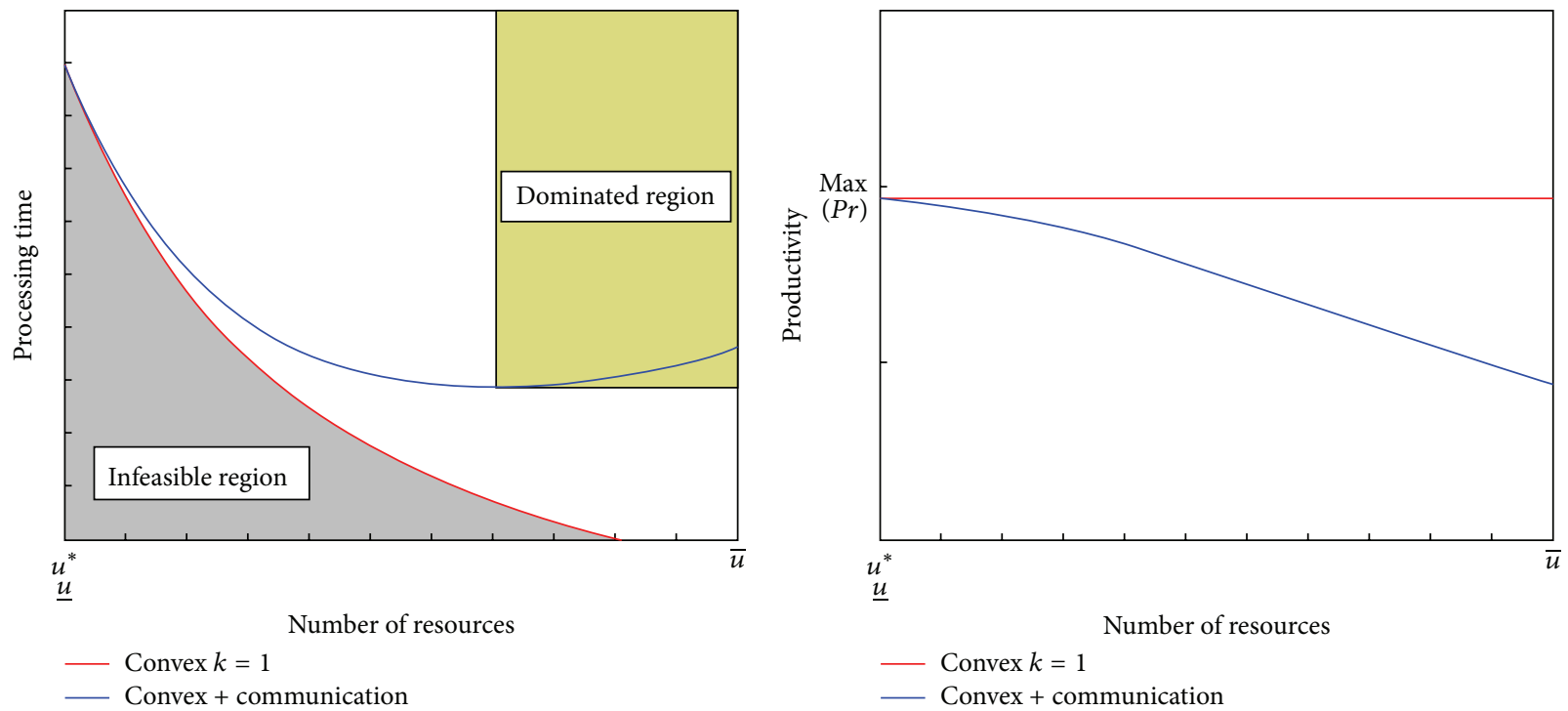

FIGURE 11: Graphic for convex plus communication.

convex + communication relation, the productive point must be in the left endpoint. To solve this problem, [17] obtained an approximated relation between the effort and the amount of resources as the following hyperbola:

$$
\left(\frac{e-h}{f}\right)^{2}-\left(\frac{u-i}{g}\right)^{2}=1,
$$

where $f, g, h$, and $i$ are constants of the problem which have to be calculated empirically. The expression for the makespan of the task depending on the amount of resources can be obtained using the definition of effort, $e=p \cdot u$ :

$$
p=\frac{h \pm f \cdot \sqrt{1+((u-i) / g)^{2}}}{u} .
$$

Analogously, the productivity can be written as

$$
\begin{aligned}
\operatorname{Pr} & =\frac{S}{p \cdot u} \\
& =\frac{S}{\left(\left(h \pm f \cdot \sqrt{1+((u-i) / g)^{2}}\right) / u\right) \cdot u} \\
& =\frac{S}{h \pm f \cdot \sqrt{1+((u-i) / g)^{2}}} .
\end{aligned}
$$

An example of this relation can be found in Figure 12. The hyperbola represents the effect of the excess of communication when allocating more employees than the productive point, but also the lack of specialization when fewer employees are used to perform the task. This translates 

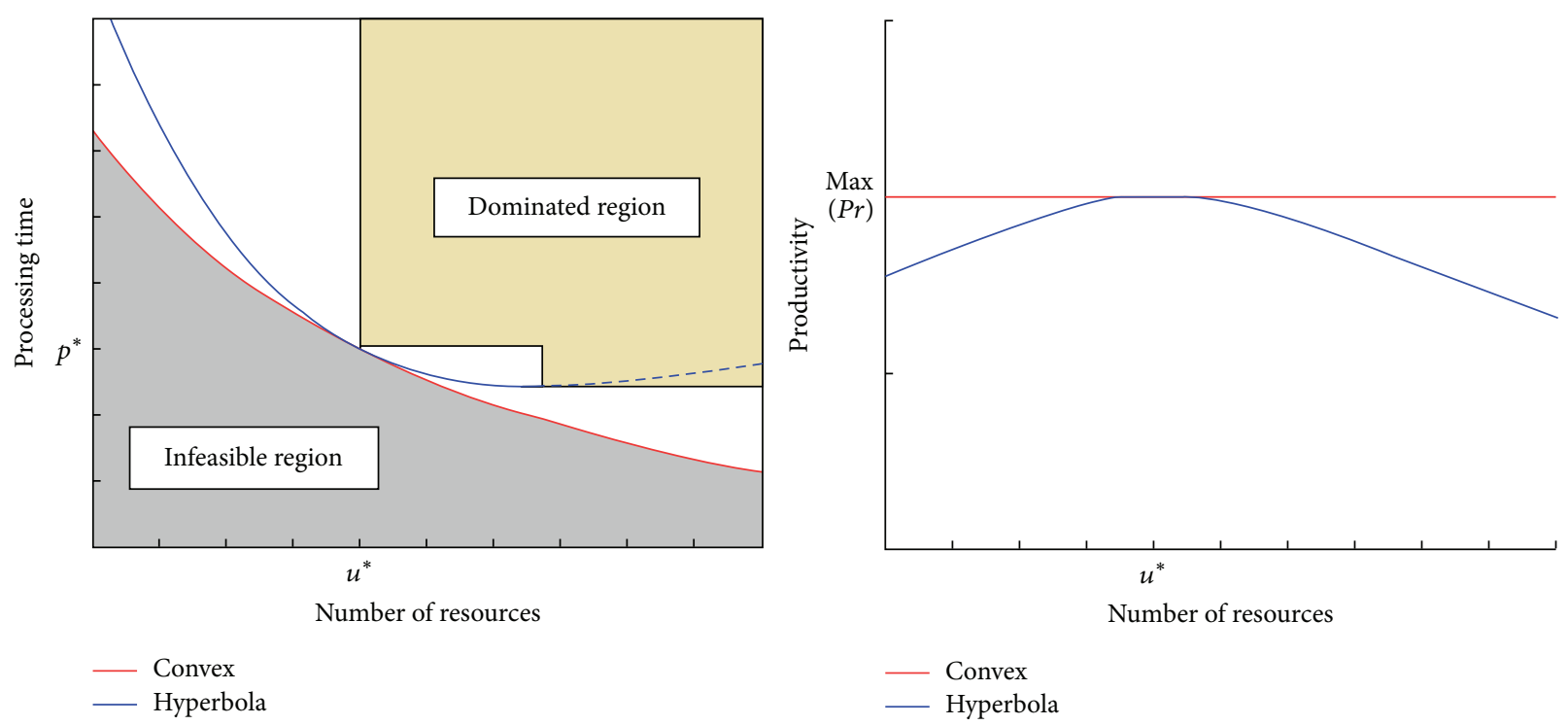

FIgURE 12: Graphic for the hyperbola.

into a better approximation of the reality. None of the aforementioned relations have adequately represented both aspects. In fact, their $u$-productivity graphics were not similar to an inverted U-shape (as [101] established). Additionally, due to the difficulty to determine the constants, an algorithm was implemented by [17] using known points $[p, u]$ for the problem. Nevertheless, it is not always possible to know previously different relations between $p$ and $u$ for the problem (due to the uncertainty of the processing times as indicated by $[39,106])$ and the determination of the constants can therefore become very difficult.

3.5. Multimode (Production and Project Management). The relation between processing times and number of discrete resources can be also treated as a multimode problem; that is, each combination of processing times and number of resources corresponds to a mode (a point in the graphic $p$ $u)$. This approach is considered for discrete renewable and nonrenewable resource in MRCPSP (see, e.g., [39-45, 48, 49]) and, specifically for discrete renewable resource, in several problems such as discrete time/resource trade-off problem DTRTP (see, e.g., [46, 47, 50-53]), project task and manpower scheduling (see [54]), identical parallel-machine scheduling (see [55]), and also MRCPSP (see, e.g., [56, 57]). This is the most generic approach for discrete resources since each possible combination between processing times and number of resources can be chosen by the decision maker and each other discrete approach (convex, linear, etc.) can be also represented by multimode. However, this approach presents two problems. First, points $p-u$ of each mode have to be known in advance, which is not always possible when several modes are considered. Second, the size of the model increases significantly due to the fact that each mode corresponds to a variable. There are many papers in the literature using multimode to treat controllable processing times depending on the number of discrete resources assigned to the task.

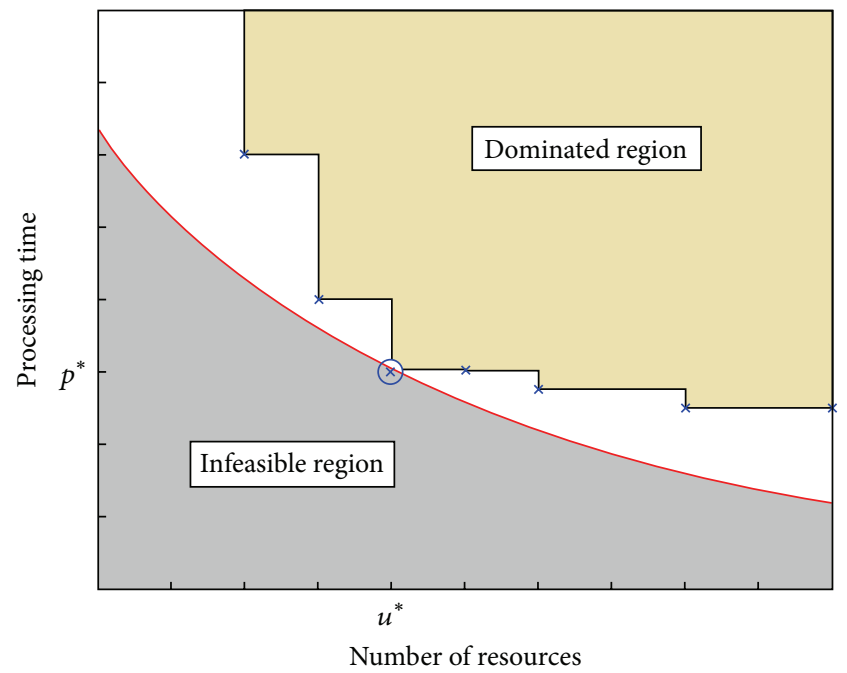

Figure 13: Graphic for multimode.

The relations between processing times and amount of resources for a task are points (modes) in a $p$ - $u$ graphic (e.g., Figure 13 with 7 modes and a single task). The point with maximum productivity could be determined by means of the point with minimum effort. Obviously, the multimode approach can be used only for discrete resources whereas other relations as linear and convex relations are equally used for discrete and continuous resources. Additionally, although there is freedom to choose the modes, the majority of these papers use an inversely proportional relation (convex with $k=1$ ) to define the modes in the problems solved in their testbeds.

3.6. Summary. In this section, we summarize the main characteristic of each relationship in Table 2. Columns 2 and 3 indicate the environment where each relation has been used, 
TABLE 2: Relations between processing times and amount of resources used in the literature.

\begin{tabular}{|c|c|c|c|c|c|c|c|c|}
\hline$p(u)$ & Production & $\begin{array}{c}\text { Project } \\
\text { management }\end{array}$ & Type of resource & $\begin{array}{c}\text { Number of } \\
\text { productive } \\
\text { points }\end{array}$ & $\begin{array}{l}\text { Productive } \\
\text { points }\end{array}$ & $\begin{array}{l}\text { Diminishing } \\
\text { marginal } \\
\text { returns law }\end{array}$ & $\begin{array}{l}\text { Inverted } \\
\text { U-shape }\end{array}$ & $\begin{array}{c}\text { Number of } \\
\text { constants }\end{array}$ \\
\hline Linear & $\mathrm{X}$ & $\mathrm{X}$ & Generic & 1 or 2 & Endpoints & Unfulfilled & $\approx \mathrm{EC}$ or LS & 2 \\
\hline Convex $k=1$ & $\mathrm{X}$ & $\mathrm{X}$ & Generic & All & Every point & Unfulfilled & Unfulfilled & 1 \\
\hline Convex $k<1$ & $\mathrm{X}$ & $\mathrm{X}$ & Generic & 1 & Left endpoint & $\begin{array}{l}\text { Partially }\left(u^{\prime}=\right. \\
\text { left endpoint) }\end{array}$ & $\approx \mathrm{EC}$ & 2 \\
\hline $\begin{array}{l}\text { Convex } k=0.5 \\
+ \text { constant }\end{array}$ & $\mathrm{X}$ & & $\begin{array}{l}\text { Nonrenewable } \\
\text { and continuous }\end{array}$ & 1 & Left endpoint & $\begin{array}{l}\text { Partially }\left(u^{\prime}=\right. \\
\text { left endpoint) }\end{array}$ & $\approx \mathrm{EC}$ & 3 \\
\hline $\begin{array}{l}\text { Convex } k=1+ \\
\text { constant }\end{array}$ & $\mathrm{X}$ & & $\begin{array}{l}\text { Nonrenewable } \\
\text { and continuous }\end{array}$ & 1 & Left endpoint & $\begin{array}{l}\text { Partially }\left(u^{\prime}=\right. \\
\text { left endpoint) }\end{array}$ & $\approx \mathrm{EC}$ & 3 \\
\hline $\begin{array}{l}\text { Convex } k=2+ \\
\text { constant }\end{array}$ & $\mathrm{X}$ & & $\begin{array}{l}\text { Nonrenewable } \\
\text { and continuous }\end{array}$ & 1 & $d / \sqrt{b}$ & $\begin{array}{c}\text { Fulfilled } \\
\left(u^{\prime}=d / \sqrt{3 \cdot b}\right)\end{array}$ & $\approx$ Fulfilled & 3 \\
\hline $\begin{array}{l}\text { Convex } k=1+ \\
\text { polynomial }\end{array}$ & & $\mathrm{X}$ & $\begin{array}{l}\text { Renewable and } \\
\text { discrete }\end{array}$ & 1 & Left endpoint & - & $\approx \mathrm{EC}$ & 2 \\
\hline Multimode & $\mathrm{X}$ & $\mathrm{X}$ & Discrete & $n$ & $\begin{array}{l}\text { Chosen by } \\
\text { the decision } \\
\text { maker }\end{array}$ & Fulfilled & Fulfilled & $n$ \\
\hline Piecewise linear & $\mathrm{X}$ & $\mathrm{X}$ & $\begin{array}{l}\text { Nonrenewable } \\
\text { and continuous }\end{array}$ & $n$ & $\begin{array}{l}\text { Point in the } \\
\text { convex curve }\end{array}$ & Fulfilled & Fulfilled & $n$ \\
\hline Hyperbola & & $\mathrm{X}$ & $\begin{array}{l}\text { Renewable and } \\
\text { discrete }\end{array}$ & 1 & $\begin{array}{l}\text { Chosen by } \\
\text { the decision } \\
\text { maker }\end{array}$ & - & Fulfilled & 4 \\
\hline
\end{tabular}

while the type of resource used is shown in column 4 . The next two columns indicate the amount of productive points in the expression and their position, respectively. 7th and 8th columns are related to the fulfillment of the diminishing marginal returns law and the inverted $\mathrm{U}$-shape, respectively. In the last column, the number of constants necessary to fulfill each $p-u$ relation has been represented. Note that a higher value of the number of constants means more difficulty to configure the model. This fact clearly explains the few papers that implement relations with 3 or more constants.

Regarding the productive configuration, we found the following.

(i) The productive configuration results in a unique productive point-which is necessarily the left endpoint-for the following configurations: convex relation with $k=0.5$, convex relation with $k=0.5+$ constant, convex relation with $k=1+$ constant, and convex relation plus communication. Hence, feasible points are only on the right of that point. Thereby, regarding project management, only the excess of communication can be modelled.

(ii) The productive configuration is placed either in one endpoint or eventually in both endpoints by the linear relation.

(iii) Convex relation with $k=1$ corresponds with the ideal boundary.

(iv) Control over the productive point is only allowed for nonrenewable resources by the convex relation with $k=2+$ constant and for renewable resources by hyperbola and multimode.
Regarding the law of diminishing marginal returns, the following aspects can be summarized.

(i) The relations that partially satisfy the law of diminishing marginal returns (only for the decreasing part of the law) are the convex relation with $k<1$, the convex relation with $k=0.5+$ constant, and the convex relation with $k=1+$ constant since the $u^{\prime}$ must be placed in the left endpoint.

(ii) The convex relation with $k=2+$ constant fulfills the diminishing marginal returns law for any amount of resources bigger than $d / \sqrt{3 \cdot b}$; that is, $u^{\prime}=d / \sqrt{3 \cdot b}$.

(iii) The linear relation, the convex relation with $k=1$, and the piecewise linear relation do not fulfill this law.

With respect to the project management environment, we noted the following.

(i) The convex relation with $k=1$ does not reflect the reality for manpower [91].

(ii) The inverted U-shape is only fulfilled by the hyperbola and the convex relation with $k=2$ plus a constant and, eventually, by the multimode and the piecewise linear relation.

(iii) The lack of specialization can be also eventually approximated by the linear relation.

\section{Conclusions}

Controllable processing times have been widely used in different environments in the literature. With respect to project 
and production management, several relations between processing times and amount of resources have been applied. However, to the best of our knowledge, the advantages, disadvantages, and properties of these relations have not been analyzed. In this paper, we have analyzed papers assuming controllable processing times in project and production management, and the different relations between processing times and the amount of resources have been classified. Due to the uncertainty in the processing times of the tasks [39], it is impossible to know exactly the relation between the processing time and the amount of resources assigned to the task and, analogously, to choose a relation over another. Approximations must be taken into account in order to represent the relations and to adapt them to solve the problems. Thereby, a total of 10 relations have been analyzed in this paper. Papers in the production management literature have mainly focused on linear and convex relations both for discrete and for continuous resources. In project management, the research has widely been focused on multimode approach.

We have defined the feasible and unfeasible regions for $p=f(u)$, as well as several definitions and properties, to be able to compare the main functions of the literature. For each one, the productivity for each amount of resources has been measured. Additionally, the law of diminishing marginal returns in the field of production management has been analyzed, together with several hypotheses for each relation in the area of the project management.

As a result, it has been shown that the most employed relation in the literature, that is, the linear one, does not fulfill the requirements of both production and project environments. Nevertheless it has been extensively used as an approximation of the reality, probably due to its simplicity and the possibility to maintain the linearity of the models. On the other hand, the assumption, widely used in the literature (see, e.g., [3, 18, 23, 27]), of applying the convex relation instead of the linear one to fulfill the law of diminishing marginal returns has been shown not to be correct and must not be further used as a justification of its consideration. Only a convex relation with $k<1$ could be considered, but only to model the decreasing part of the law, that is, from $u^{\prime}$ on. When a constant is added to the expression, the law can be fulfilled by the configuration $k=2+$ constant where the point $u^{\prime}$ is equal to $d / \sqrt{3 \cdot b}$. Something similar happens regarding project management, since the $u$-productivity graphic is only similar to an inverted U-shape for the configuration $k=$ $2+$ constant. However, to the best of our knowledge this configuration has not been used yet. In this regard, the best relation related to $u$-productivity graphic is achieved by the hyperbola. Nevertheless, the high number of constants (four) needed for its configuration makes it difficult to use since at least four $p-u$ points should be known in advance. This is similar to the multimode and piecewise linear relations, which obviously have the most complete configuration in order to model the $p-u$ relation since the decision maker can adapt these relations in function of the studied problem. This last aspect also remarks the great importance of the previous knowledge of the problem (i.e., which $p$ - $u$ points are known) when choosing the relation to be applied.
Finally, regarding the future research lines of this paper, new relations may be considered for discrete resources since there are almost no papers using them. In addition, to the best of our knowledge, only the hyperbola has been used to represent the inverted U-shape of the productivity in project management. Due to the difficulties to determine the constants of this relation, new relations may be considered in order to represent the excess of communication and the lack of specialization together as, for example, the convex relation with $k=2+$ constant.

\section{Conflict of Interests}

The authors declare that there is no conflict of interests regarding the publication of this paper.

\section{References}

[1] R. J. Tersine and E. A. Hummingbird, "Lead-time reduction: the search for competitive advantage," International Journal of Operations and Production Management, vol. 15, no. 2, pp. 8-18, 1995.

[2] C. H. Glock, "Lead time reduction strategies in a single-vendorsingle-buyer integrated inventory model with lot size-dependent lead times and stochastic demand," International Journal of Production Economics, vol. 136, no. 1, pp. 37-44, 2012.

[3] Y. Leyvand, D. Shabtay, and G. Steiner, "A unified approach for scheduling with convex resource consumption functions using positional penalties," European Journal of Operational Research, vol. 206, no. 2, pp. 301-312, 2010.

[4] E. Nowicki and S. Zdrzalka, "A survey of results for sequencing problems with controllable processing times," Discrete Applied Mathematics, vol. 26, no. 2-3, pp. 271-287, 1990.

[5] F. P. Brooks Jr., The Mythical Man-Month: Essays on Software Engineering, 1975.

[6] P. Hsia, C.-T. Hsu, and D. C. Kung, "Brooks' law revisited: a system dynamics approach," in Proceedings of the 23rd Annual International Computer Software and Applications Conference (COMPSAC '99), pp. 370-375, IEEE, Phoenix, Ariz, USA, October 1999.

[7] D. Rodríguez, M. A. Sicilia, E. García, and R. Harrison, "Empirical findings on team size and productivity in software development," Journal of Systems and Software, vol. 85, no. 3, pp. 562570, 2012.

[8] M. S. Akturk and T. Ilhan, "Single CNC machine scheduling with controllable processing times to minimize total weighted tardiness," Computers \& Operations Research, vol. 38, no. 4, pp. 771-781, 2011.

[9] Y. Kara, C. Özgüven, N. Yalçin, and Y. Atasagun, "Balancing straight and U-shaped assembly lines with resource dependent task times," International Journal of Production Research, vol. 49, no. 21, pp. 6387-6405, 2011.

[10] A. Drexl, "Scheduling of project networks by job assignment," Management Science, vol. 37, no. 12, pp. 1590-1602, 1991.

[11] B. Dodin and A. A. Elimam, "Audit scheduling with overlapping activities and sequence-dependent setup costs," European Journal of Operational Research, vol. 97, no. 1, pp. 22-33, 1997.

[12] C. Heimerl and R. Kolisch, "Work assignment to and qualification of multi-skilled human resources under knowledge depreciation and company skill level targets," International Journal of Production Research, vol. 48, no. 13, pp. 3759-3781, 2010. 
[13] V. Valls, Á. Pérez, and S. Quintanilla, "Skilled workforce scheduling in Service Centres," European Journal of Operational Research, vol. 193, no. 3, pp. 791-804, 2009.

[14] J. Blazewicz, K. H. Ecker, E. Pesch, G. Schmidt, and J. Weglarz, Handbook on Scheduling, Springer, Berlin, Germany, 2007.

[15] R. Slowinski, "Two approaches to problems of resource allocation among project activities-a comparative study," Operational Research Society Journal, vol. 31, no. 8, pp. 711-723, 1980.

[16] D. Shabtay and G. Steiner, "A survey of scheduling with controllable processing times," Discrete Applied Mathematics, vol. 155, no. 13, pp. 1643-1666, 2007.

[17] M. Hericko, A. Živkovic, and I. Rozman, "An approach to optimizing software development team size," Information Processing Letters, vol. 108, no. 3, pp. 101-106, 2008.

[18] C. L. Monma, A. Schrijver, M. J. Todd, and V. K. Wei, "Convex resource allocation problems on directed acyclic graphs: duality, complexity, special cases, and extensions," Mathematics of Operations Research, vol. 15, no. 4, pp. 736-748, 1990.

[19] C.-Y. Lee and L. Lei, "Multiple-project scheduling with controllable project duration and hard resource constraint: some solvable cases," Annals of Operations Research, vol. 102, pp. 287307, 2001.

[20] A. Živkovič, I. Rozman, and M. Heričko, "Automated software size estimation based on function points using UML models," Information and Software Technology, vol. 47, no. 13, pp. 881890, 2005.

[21] B. Boehm, B. Clark, E. Horowitz, C. Westland, R. Madachy, and R. Selby, "Cost models for future software life cycle processes: COCOMO 2.0," Annals of Software Engineering, vol. 1, no. 1, pp. 57-94, 1995.

[22] Y. Ahn, J. Suh, S. Kim, and H. Kim, "The software maintenance project effort estimation model based on function points," Journal of Software Maintenance and Evolution, vol. 15, no. 2, pp. 71-85, 2003.

[23] K. Xu, Z. Feng, and K. Jun, "A tabu-search algorithm for scheduling jobs with controllable processing times on a single machine to meet due-dates," Computers \& Operations Research, vol. 37, no. 11, pp. 1924-1938, 2010.

[24] D. Shabtay, "Single and two-resource allocation algorithms for minimizing the maximal lateness in a single machine," Computers and Operations Research, vol. 31, no. 8, pp. 1303-1315, 2004.

[25] Y. Yin, T. C. E. Cheng, C.-C. Wu, and S.-R. Cheng, "Singlemachine common due-date scheduling with batch delivery costs and resource-dependent processing times," International Journal of Production Research, vol. 51, no. 17, pp. 5083-5099, 2013.

[26] D. Shabtay and G. Steiner, "The single-machine earlinesstardiness scheduling problem with due date assignment and resource-dependent processing times," Annals of Operations Research, vol. 159, pp. 25-40, 2008.

[27] D. Shabtay and M. Kaspi, "Minimizing the total weighted flow time in a single machine with controllable processing times," Computers \& Operations Research, vol. 31, no. 13, pp. 2279-2289, 2004.

[28] D. Shabtay, M. Kaspi, and G. Steiner, "The no-wait two-machine flow shop scheduling problem with convex resource-dependent processing times," IIE Transactions, vol. 39, no. 5, pp. 539-557, 2007.

[29] M. Kaspi and D. Shabtay, "A bicriterion approach to time/cost trade-offs in scheduling with convex resource-dependent job processing times and release dates," Computers and Operations Research, vol. 33, no. 10, pp. 3015-3033, 2006.

[30] D. Shabtay and G. Steiner, "A bicriteria approach to minimize the total weighted number of tardy jobs with convex controllable processing times and assignable due dates," Journal of Scheduling, vol. 14, no. 5, pp. 455-469, 2011.

[31] D. Shabtay and M. Kaspi, "Parallel machine scheduling with a convex resource consumption function," European Journal of Operational Research, vol. 173, no. 1, pp. 92-107, 2006.

[32] D. Shabtay and M. Kaspi, "Minimizing the makespan in openshop scheduling problems with a convex resource consumption function," Naval Research Logistics, vol. 53, no. 3, pp. 204-216, 2006.

[33] D. Wang, M.-Z. Wang, and J.-B. Wang, "Single-machine scheduling with learning effect and resource-dependent processing times," Computers and Industrial Engineering, vol. 59, no. 3, pp. 458-462, 2010.

[34] Y.-Y. Lu, G. Li, Y.-B. Wu, and P. Ji, “Optimal due-date assignment problem with learning effect and resource-dependent processing times," Optimization Letters, vol. 8, no. 1, pp. 113-127, 2014.

[35] Z. Zhu, L. Sun, F. Chu, and M. Liu, "Single-machine group scheduling with resource allocation and learning effect," Computers and Industrial Engineering, vol. 60, no. 1, pp. 148-157, 2011.

[36] M. Kaspi and D. Shabtay, "Convex resource allocation for minimizing the makespan in a single machine with job release dates," Computers \& Operations Research, vol. 31, no. 9, pp. 1481$1489,2004$.

[37] X.-R. Wang and J.-J. Wang, "Single-machine scheduling with convex resource dependent processing times and deteriorating jobs," Applied Mathematical Modelling, vol. 37, no. 4, pp. 23882393, 2013.

[38] L. Yedidsion, D. Shabtay, E. Korach, and M. Kaspi, "A bicriteria approach to minimize number of tardy jobs and resource consumption in scheduling a single machine," International Journal of Production Economics, vol. 119, no. 2, pp. 298-307, 2009.

[39] F. Deblaere, E. Demeulemeester, and W. Herroelen, "Reactive scheduling in the multi-mode RCPSP," Computers \& Operations Research, vol. 38, no. 1, pp. 63-74, 2011.

[40] Y. Li, S. Zhang, X. Zhang, and L. Luo, "Multi-mode resourceconstrained scheduling for complex product design tasks," Advanced Materials Research, vol. 129-131, pp. 566-571, 2010.

[41] L. Wang and C. Fang, "An effective estimation of distribution algorithm for the multi-mode resource-constrained project scheduling problem," Computers and Operations Research, vol. 39, pp. 449-460, 2012.

[42] V. van Peteghem and M. Vanhoucke, "A genetic algorithm for the preemptive and non-preemptive multi-mode resource-constrained project scheduling problem," European Journal of Operational Research, vol. 201, no. 2, pp. 409-418, 2010.

[43] B. de Reyck and W. Herroelen, "Multi-mode resource-constrained project scheduling problem with generalized precedence relations," European Journal of Operational Research, vol. 119, no. 2, pp. 538-556, 1999.

[44] R. Kolisch and A. Drexl, "Local for multi-mode resourceconstrained project," IIE Transactions (Institute of Industrial Engineers), vol. 29, no. 11, pp. 987-999, 1997.

[45] A. Sprecher and A. Drexl, "Multi-mode resource-constrained project scheduling by a simple, general and powerful sequencing algorithm," European Journal of Operational Research, vol. 107, no. 2, pp. 431-450, 1998. 
[46] E. Demeulemeester, B. De Reyck, and W. Herroelen, "The discrete time/resource trade-off problem in project networks: a branch-and-bound approach," IIE Transactions (Institute of Industrial Engineers), vol. 32, no. 11, pp. 1059-1069, 2000.

[47] M. R. Ranjbar and F. Kianfar, "Solving the discrete time/resource trade-off problem in project scheduling with genetic algorithms," Applied Mathematics and Computation, vol. 191, no. 2, pp. 451-456, 2007.

[48] N. Nudtasomboon and S. U. Randhawa, "Resource-constrained project scheduling with renewable and non-renewable resources and time-resource tradeoffs," Computers and Industrial Engineering, vol. 32, no. 1, pp. 227-242, 1997.

[49] A. Sprecher, S. Hartmann, and A. Drexl, "An exact algorithm for project scheduling with multiple modes," OR Spektrum, vol. 19, no. 3, pp. 195-203, 1997.

[50] B. de Reyck, E. Demeulemeester, and W. Herroelen, "Local search methods for the discrete time/resource trade-off problem in project networks," Naval Research Logistics, vol. 45, no. 6, pp. 552-578, 1998.

[51] M. Ranjbar, B. de Reyck, and F. Kianfar, "A hybrid scatter search for the discrete time/resource trade-off problem in project scheduling," European Journal of Operational Research, vol. 193, no. 1, pp. 35-48, 2009.

[52] P. Wuliang and W. Chengen, "A multi-mode resource-constrained discrete time-cost tradeoff problem and its genetic algorithm based solution," International Journal of Project Management, vol. 27, no. 6, pp. 600-609, 2009.

[53] F. B. Talbot, "Resource-Constrained project scheduling with time-resource tradeoffs: the nompreemptive case," Management Science, vol. 28, no. 10, pp. 1197-1210, 1982.

[54] H. K. Alfares and J. E. Bailey, "Integrated project task and manpower scheduling," IIE Transactions, vol. 29, no. 9, pp. 711-717, 1997.

[55] H. Kellerer, "An approximation algorithm for identical parallel machine scheduling with resource dependent processing times," Operations Research Letters, vol. 36, no. 2, pp. 157-159, 2008.

[56] S. Baradaran, S. M. T. F. Ghomi, M. Ranjbar, and S. S. Hashemin, "Multi-mode renewable resource-constrained allocation in PERT networks," Applied Soft Computing Journal, vol. 12, no. 1, pp. 82-90, 2012.

[57] F. F. Boctor, "A new and efficient heuristic for scheduling projects with resource restrictions and multiple execution modes," European Journal of Operational Research, vol. 90, no. 2, pp. 349-361, 1996.

[58] R. L. Daniels and R. K. Sarin, "Single machine scheduling with controllable processing times and number of jobs tardy," Operations Research, vol. 37, no. 6, pp. 981-984, 1989.

[59] A. Janiak and M. Y. Kovalyov, "Single machine scheduling subject to deadlines and resource dependent processing times," European Journal of Operational Research, vol. 94, no. 2, pp. 284-291, 1996.

[60] K. Li, Y. Shi, S.-L. Yang, and B.-Y. Cheng, "Parallel machine scheduling problem to minimize the makespan with resource dependent processing times," Applied Soft Computing Journal, vol. 11, no. 8, pp. 5551-5557, 2011.

[61] H. Mokhtari, I. N. K. Abadi, and A. Cheraghalikhani, "A multiobjective flow shop scheduling with resource-dependent processing times: trade-off between makespan and cost of resources," International Journal of Production Research, vol. 49, no. 19, pp. 5851-5875, 2011.
[62] C. T. Ng, T. C. Cheng, A. Janiak, and M. Y. Kovalyov, "Group scheduling with controllable setup and processing times: minimizing total weighted completion time," Annals of Operations Research, vol. 133, pp. 163-174, 2005.

[63] N. Yin and X.-Y. Wang, "Single-machine scheduling with controllable processing times and learning effect," The International Journal of Advanced Manufacturing Technology, vol. 54, no. 5-8, pp. 743-748, 2011.

[64] C.-M. Wei, J.-B. Wang, and P. Ji, "Single-machine scheduling with time-and-resource-dependent processing times," Applied Mathematical Modelling, vol. 36, no. 2, pp. 792-798, 2012.

[65] C.-T. Tseng, C.-J. Liao, and K.-L. Huang, "Minimizing total tardiness on a single machine with controllable processing times," Computers \& Operations Research, vol. 36, no. 6, pp. 1852-1858, 2009.

[66] I. Mahdavi, V. Kayvanfar, and G. M. Komaki, "Minimizing total tardiness and earliness problem with controllable processing times using an effective heuristic," in Proceedings of the 40th International Conference on Computers and Industrial Engineering (CIE40 '10), pp. 1-4, July 2010.

[67] T. C. Cheng, M. Y. Kovalyov, and N. V. Shakhlevich, "Scheduling with controllable release dates and processing times: total completion time minimization," European Journal of Operational Research, vol. 175, no. 2, pp. 769-781, 2006.

[68] G. I. Adamopoulos, C. P. Pappis, and N. I. Karacapilidis, "Job sequencing with uncertain and controllable processing times," International Transactions in Operational Research, vol. 6, no. 5, pp. 483-493, 1999.

[69] L. N. van Wassenhove and K. R. Baker, "A bicriterion approach to time/cost trade-offs in sequencing," European Journal of Operational Research, vol. 11, no. 1, pp. 48-54, 1982.

[70] B.-C. Choi, S.-H. Yoon, and S.-J. Chung, "Single machine scheduling problem with controllable processing times and resource dependent release times," European Journal of Operational Research, vol. 181, no. 2, pp. 645-653, 2007.

[71] R. G. Vickson, "Choosing the job sequence and processing times to minimize total processing plus flow cost on a single machine," Operations Research, vol. 28, no. 5, pp. 1155-1167, 1980.

[72] T. C. E. Cheng, C. Oguz, and X. D. Qi, "Due-date assignment and single machine scheduling with compressible processing times," International Journal of Production Economics, vol. 43, no. 1, pp. 29-35, 1996.

[73] S. S. Panwalkar and R. Rajagopalan, "Single-machine sequencing with controllable processing times," European Journal of Operational Research, vol. 59, no. 2, pp. 298-302, 1992.

[74] S. D. Liman, S. S. Panwalkar, and S. Thongmee, "A single machine scheduling problem with common due window and controllable processing times," Annals of Operations Research, vol. 70, pp. 145-154, 1997.

[75] G. Wan, B. P. Yen, and C.-L. Li, "Single machine scheduling to minimize total compression plus weighted flow cost is NPhard," Information Processing Letters, vol. 79, no. 6, pp. 273-280, 2001.

[76] X. Wang and T. C. Cheng, "Single machine scheduling with resource dependent release times and processing times," European Journal of Operational Research, vol. 162, no. 3, pp. 727-739, 2005.

[77] F. Kolahan and M. Liang, "An adaptive TS approach to JIT sequencing with variable processing times and sequencedependent setups," European Journal of Operational Research, vol. 109, no. 1, pp. 142-159, 1998. 
[78] Y. He, Q. Wei, and T. C. Cheng, "Single-machine scheduling with trade-off between number of tardy jobs and compression cost," Journal of Scheduling, vol. 10, no. 4-5, pp. 303-310, 2007.

[79] J.-B. Wang, "Single machine scheduling with common due date and controllable processing times," Applied Mathematics and Computation, vol. 174, no. 2, pp. 1245-1254, 2006.

[80] A. C. Nearchou, "Scheduling with controllable processing times and compression costs using population-based heuristics," International Journal of Production Research, vol. 48, no. 23, pp. 7043-7062, 2010.

[81] G. Wan, S. R. Vakati, J. Y. Leung, and M. Pinedo, "Scheduling two agents with controllable processing times," European Journal of Operational Research, vol. 205, no. 3, pp. 528-539, 2010.

[82] J. Behnamian and S. M. Fatemi Ghomi, "Hybrid flowshop scheduling with machine and resource-dependent processing times," Applied Mathematical Modelling. Simulation and Computation for Engineering and Environmental Systems, vol. 35, no. 3, pp. 1107-1123, 2011.

[83] T. C. E. Cheng, A. Janiak, and M. Y. Kovalyov, "Bicriterion single machine scheduling with resource dependent processing times," SIAM Journal on Optimization, vol. 8, no. 2, pp. 617-630, 1998.

[84] L.-H. Su and C.-Y. Lien, "Scheduling parallel machines with resource-dependent processing times," International Journal of Production Economics, vol. 117, no. 2, pp. 256-266, 2009.

[85] T. C. E. Cheng, A. Janiak, and M. Y. Kovalyov, "Single machine batch scheduling with resource dependent setup and processing times," European Journal of Operational Research, vol. 135, no. 1, pp. 177-183, 2001.

[86] J. N. D. Gupta, K. Krüger, V. Lauff, F. Werner, and Y. N. Sotskov, "Heuristics for hybrid flow shops with controllable processing times and assignable due dates," Computers and Operations Research, vol. 29, no. 10, pp. 1417-1439, 2002.

[87] A. Janiak, M. Y. Kovalyov, and M.-C. Portmann, "Single machine group scheduling with resource dependent setup and processing times," European Journal of Operational Research, vol. 162, no. 1, pp. 112-121, 2005.

[88] V. Fernandez-Viagas and J. M. Framinan, "Integrated project scheduling and staff assignment with controllable processing times," Scientific World Journal, vol. 2014, Article ID 924120, 16 pages, 2014.

[89] J. J. Moder, C. R. Phillips, and E. W. Davis, Project Management with Cpm, Pert and Precedence Diagramming, Van NostrandReinhold, New York, NY, USA, 3rd edition, 1983.

[90] M. di Penta, M. Harman, G. Antoniol, and F. Qureshi, “The effect of communication overhead on software maintenance project staffing: a search-based approach," in Proceedings of the 23rd International Conference on Software Maintenance (ICSM '07), pp. 315-324, October 2007.

[91] M. J. Lanigan, “Task estimating: completion time versus team size," Engineering Management Journal, vol. 4, no. 5, pp. 212-218, 1994.

[92] P. C. Pendharkar and J. A. Rodger, "An empirical study of the impact of team size on software development effort," Information Technology and Management, vol. 8, no. 4, pp. 253-262, 2007.

[93] T. E. Hastings and A. S. M. Sajeev, "A vector-based approach to software size measurement and effort estimation," IEEE Transactions on Software Engineering, vol. 27, no. 4, pp. 337-350, 2001.
[94] M. A. Parthasarathy, Practical Software Estimation: Function Points Methods for Insourced and Outsourced Projects, AddisonWesley Professional, 2007.

[95] B. Kitchenham and E. Mendes, "Software productivity measurement using multiple size measures," IEEE Transactions on Software Engineering, vol. 30, no. 12, pp. 1023-1035, 2004.

[96] A. MacCormack, C. F. Kemerer, M. Cusumano, and B. Crandall, "Trade-offs between productivity and quality in selecting software development practices," IEEE Software, vol. 20, no. 5, pp. 78-85, 2003.

[97] S. Hartmann and D. Briskorn, "A survey of variants and extensions of the resource-constrained project scheduling problem," European Journal of Operational Research, vol. 207, no. 1, pp. 1$14,2010$.

[98] R. A. Bilas, Microeconomic Theory, McGraw-Hill, 2nd edition, 1971.

[99] L. Milgram, A. Spector, and M. Treger, "Law of diminishing returns," in Managing Smart Anonymous, p. 51, Gulf Professional Publishing, Boston, Mass, USA, 1999.

[100] R. S. Pindyck and L. D. Rubinfeld, Microeconomics, Prentice Hall, 7th edition, 2008.

[101] V. F. Nieva, E. A. Fleishman, and A. Rieck, Team Dimensions: Their Identity, Their Measurement and Their Relationships, Advanced Research Resources Organizations, Washington, DC, USA, 1985.

[102] R. M. Belbin, Management Teams, Butterworth-Heinemann, Amsterdam, The Netherlands, 2010.

[103] K. G. Smith, K. A. Smith, J. D. Olian, H. P. Sims, D. P. O’Bannon, and J. A. Scully, "Top management team demography and process: the role of social integration and communication," Administrative Science Quarterly, vol. 39, no. 3, pp. 412-438, 1994.

[104] L. Fried, "Team size and productivity in systems development. Bigger does not always mean better," Journal of Information Systems Management, vol. 8, pp. 27-35, 1991.

[105] M. A. Cusumano and R. W. Selby, Microsoft Secrets, The Free Press, New York, NY, USA, 1995.

[106] S. R. Lawrence and E. C. Sewell, "Heuristic, optimal, static, and dynamic schedules when processing times are uncertain," Journal of Operations Management, vol. 15, no. 1, pp. 71-82, 1997. 


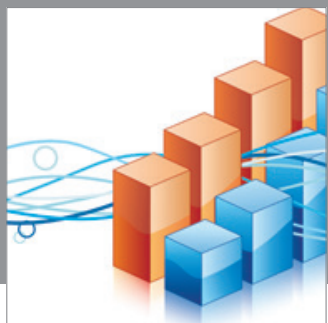

Advances in

Operations Research

mansans

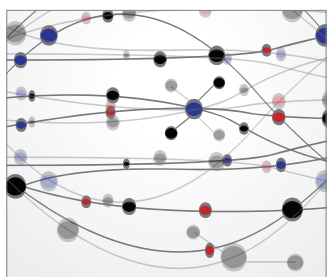

The Scientific World Journal
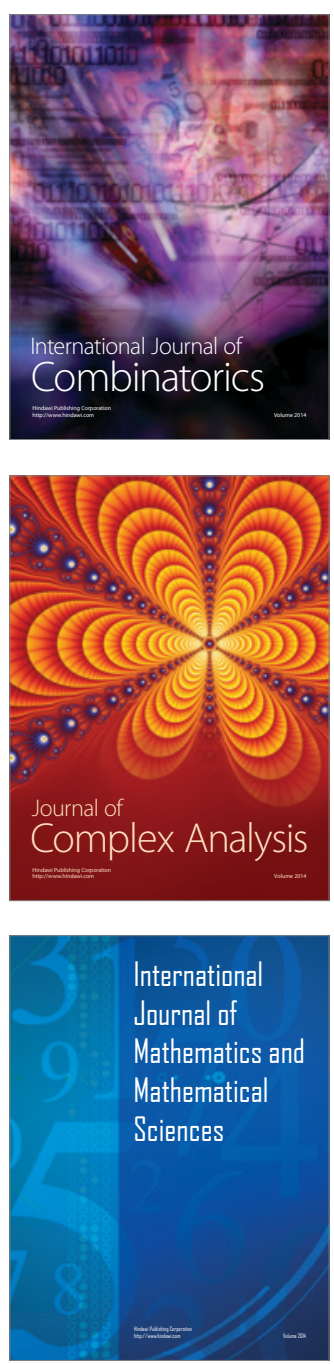
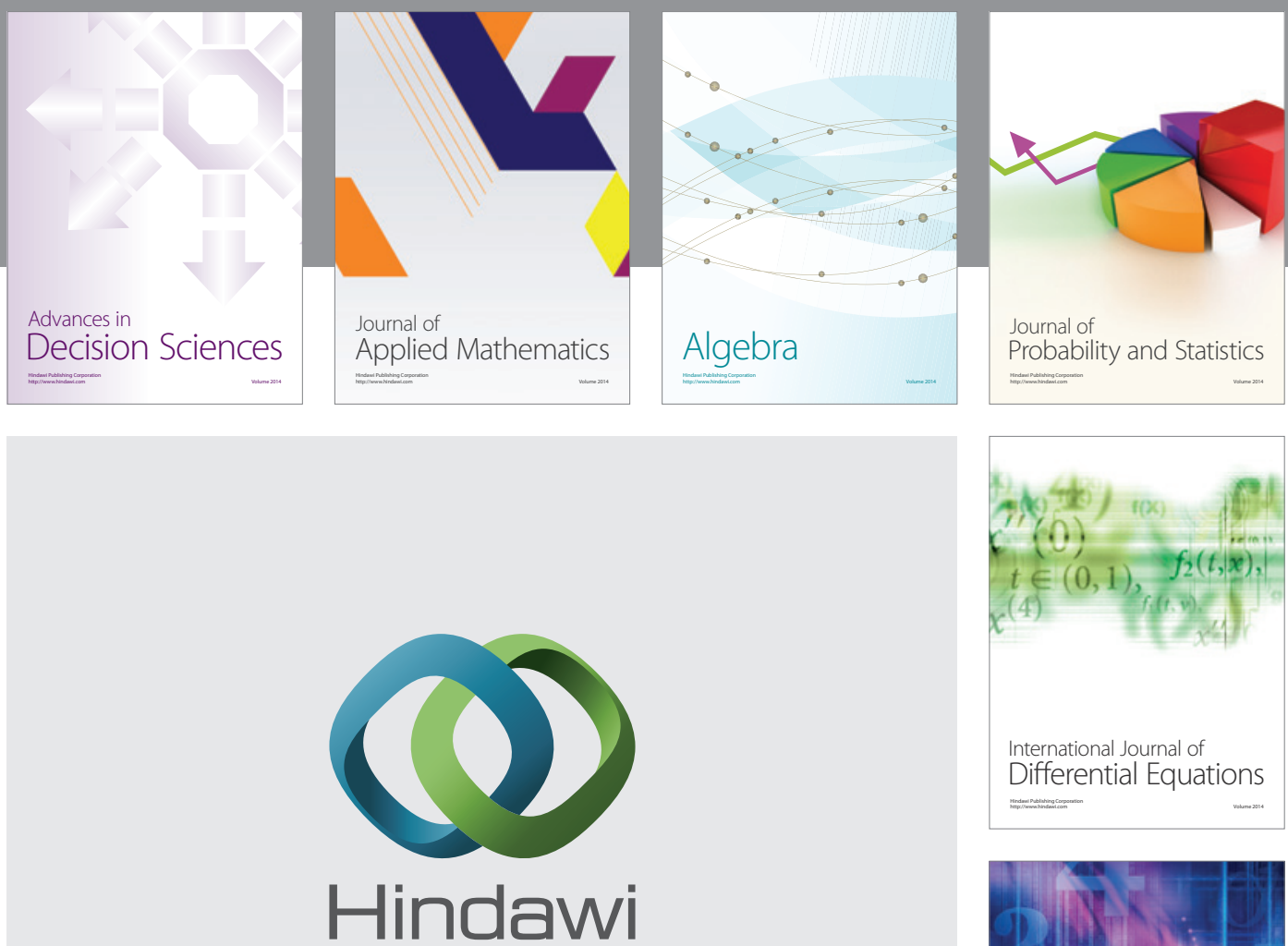

Submit your manuscripts at http://www.hindawi.com
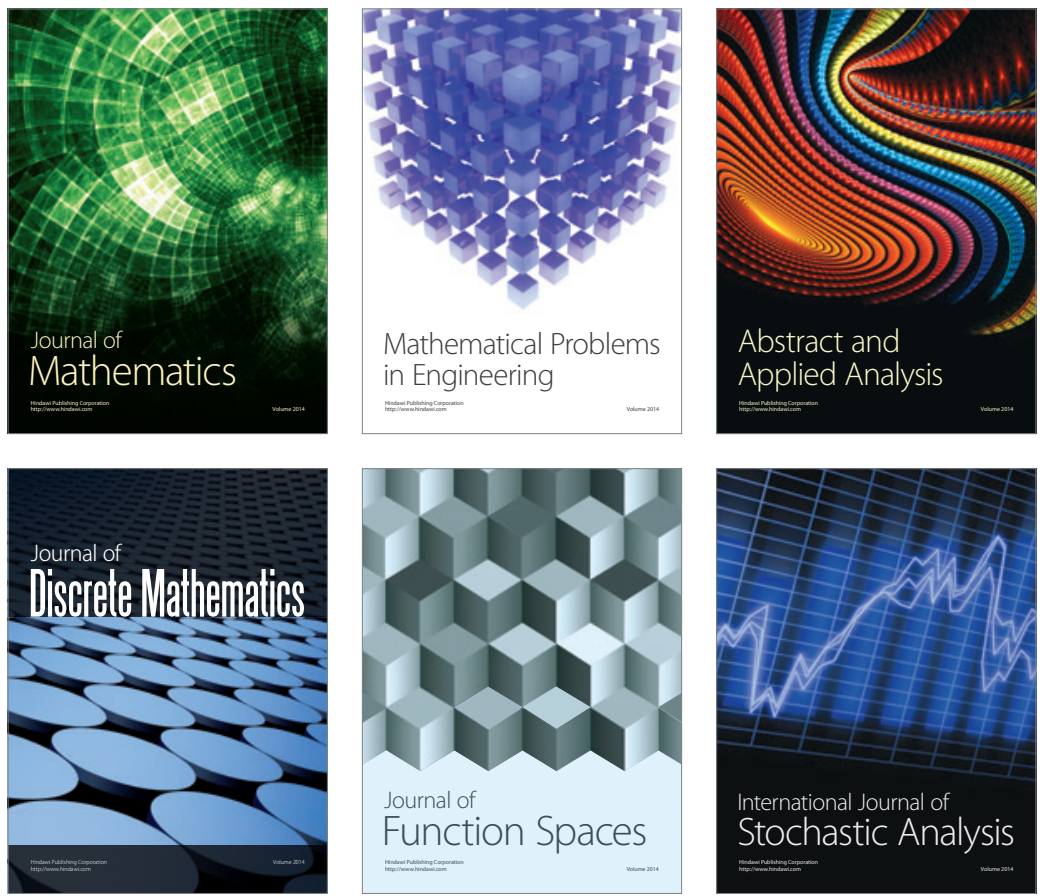

Journal of

Function Spaces

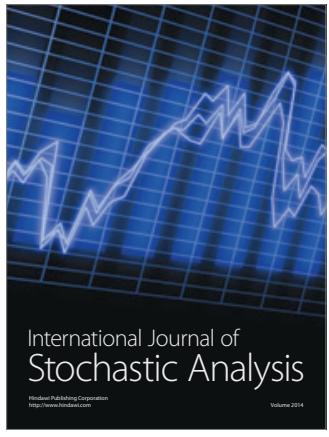

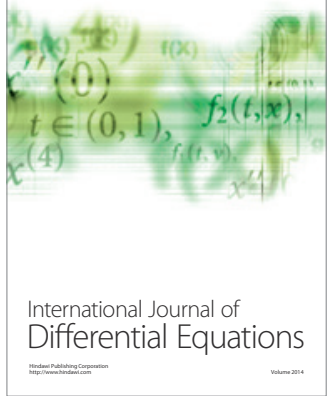
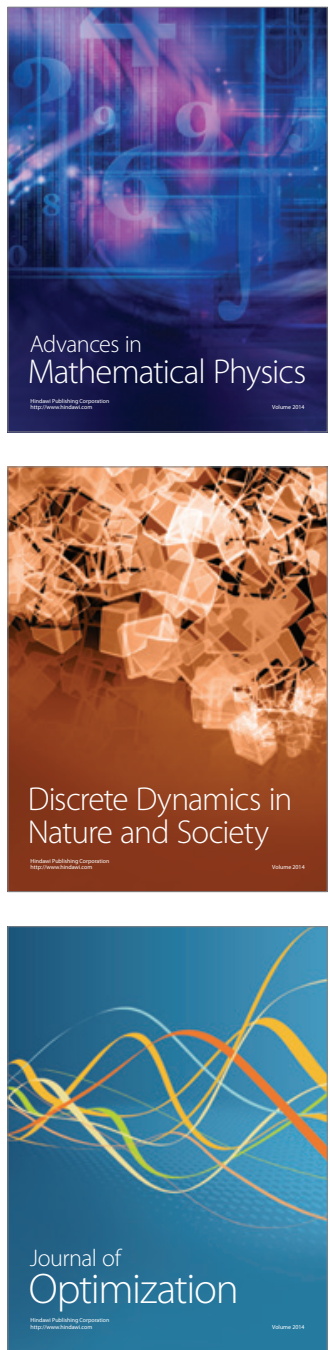